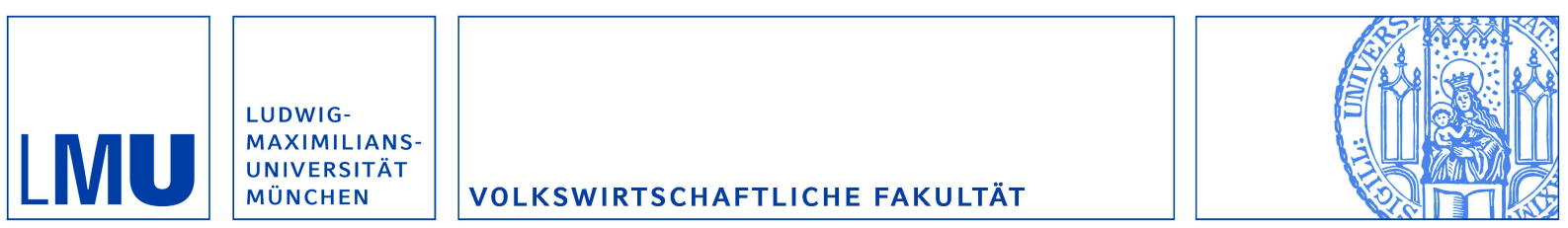

Ispano, Alessandro und Schwardmann, Peter:

Cooperating over losses and competing over gains: a social dilemma experiment

Munich Discussion Paper No. 2016-2

Department of Economics

University of Munich

Volkswirtschaftliche Fakultät

Ludwig-Maximilians-Universität München

Online at https://doi.org/10.5282/ubm/epub.27576 


\title{
Cooperating over losses and competing over gains: a social dilemma experiment*
}

\author{
Alessandro Ispano ${ }^{\dagger} \quad$ Peter Schwardmann ${ }^{\ddagger}$
}

March 2016

\begin{abstract}
Evidence from studies in international relations, the politics of reform, collective action and price competition suggests that economic agents in social dilemma situations cooperate more to avoid losses than in the pursuit of gains. To test whether the prospect of losses can induce cooperation, we let experimental subjects play the traveler's dilemma in the gain and loss domain. Subjects cooperate substantially more over losses. Our experimental design allows us to show that this treatment effect is best explained by reference-dependent risk preferences and referencedependent strategic sophistication. We discuss policy implications and relate our findings to other experimental games played in the loss domain.
\end{abstract}

Keywords: cooperation, traveler's dilemma, social dilemma, loss domain, diminishing sensitivity, cognitive hierarchy

JEL classification: C90, D01, D03, D81

*We thank Giuseppe Attanasi, Astrid Hopfensitz, Hannah Braun, Antonio Cabrales, Pascal Lavergne, Sébastien Pouget, Paul Seabright, Frances Spies, Johannes Spinnewijn, Klaus Schmidt and Jean Tirole as well as seminar participants at the Toulouse School of Economics, Paris School of Economics, CREST, ECORE, LMU Munich, the ESA World Meeting in Zürich, Journees de Microeconomie Appliquee 2014, the Annual Meeting of the AFSE 2014 and the European Meeting of the Econometric Society 2014 for useful comments. We received funding from the grant ANR: 2010 JCJC 180301 TIES.

${ }^{\dagger}$ CREST, 15 Boulevard Gabriel Péri, 92245 Malakoff, France; email: alessandro.ispano@gmail.com.

${ }_{\ddagger}^{\ddagger}$ Department of Economics, LMU Munich, Ludwigstr. 28, D-80539 Munich, Germany; email: pschwardmann@gmail.com. 


\section{Introduction}

In many important contexts it is socially efficient for two or more agents to cooperate, yet the cooperative outcome leaves each agent with an incentive to deviate at the expense of the others. How cooperation can be sustained in such social dilemmas has been the focus of several literatures across the social sciences. But one empirical observation has thus far evaded a convincing unifying explanation: cooperation thrives when agents perceive themselves to be in the loss domain.

A number of studies in international relations find that the threat of losses, more than the promise of gains, induces national governments to cooperate on multilateral economic surveillance and military strategy (Stein and Pauly, 1992; Mercer, 2005). ${ }^{1}$

Within countries, reforms are often spurred by crises (Weyland, 2002; Vis, 2009). Where inefficient policies are the non-cooperative outcome of a game between political stakeholders, crises can bring about a switch to more cooperative policymaking (Velasco, 1998; Tommasi, 2004). Being put in the loss domain by a crisis appears to equip policy makers, the electorate and other stakeholders with the risk tolerance required to pursue risky reforms and cooperation (Weyland, 1996; Tommasi, 2004; Vis and Van Kersbergen, 2007).

Collective action to revolt seems puzzling in light of individuals' incentives to freeride or defect (Coleman, 1994; Moore, 1995). According to Berejikian (1992) and Fanis (2004) it is the threat of losses that helps individuals overcome the freeriding problem and engage in a revolt. In the context of organised labor, the credible threat of a strike in response to wage cuts may help explain the downward stickiness of wages. $^{2}$

Price competition between firms is less fierce during economic downturns (Rotemberg and Saloner, 1986). ${ }^{3}$ Bertrand competition is a social dilemma and bad demand conditions may lead to more cooperative, or collusive, outcomes, because they put managers in the loss domain.

Of course, these examples admit separate explanations that do not rely on

\footnotetext{
${ }^{1}$ It has been argued that the threat of losses motivated the international cooperation of setting up the Bretton Woods agreement (Pauly, 1992); lead to the Structural Impediments Initiative of 1989-1990, which saw Japan and the United States agree to costly domestic reforms in order to facilitate a better trading relationship (Mastanduno, 1992); and was the foundation of Israel's cooperation with the US during the Gulf war (Welch, 1992).

${ }^{2}$ Kahn (1997) documents workers' and firms' resistance to nominal pay cuts and interprets it as evidence that current wage levels constitute an important reference point. Bewley (2002) provides additional evidence and explanations for the downward rigidity of wages.

${ }^{3}$ Rojas (2012) and Ruffle (2013) show this effect in experimental games. Rotemberg and Saloner (1986) explain it as the outcome of a repeated game, in which low demand decreases the temptation to cheat.
} 
whether agents perceive payoffs as gains or as losses. Moreover, the causal impact of losses on strategic behaviour is hard to establish in the field. We therefore conduct a controlled laboratory experiment that has subjects play a once-off, anonymous social dilemma and varies exogenously whether payoffs are framed as gains or as losses. Our experiment is also designed to investigate how the prospect of losses impacts on cooperation.

We find that subjects cooperate substantially more in the loss domain and that this treatment effect is driven by subjects exhibiting 1) greater risk tolerance and 2) less strategic sophistication when losses are at stake. Strategic uncertainty or noisy decision making imply that moving away from the least cooperative action of our experimental game may yield a higher expected payoff. But cooperation also exposes a player to the downside risk of being undercut. Because our subjects are more risk tolerant over losses, as implied by prospect theory's diminishing sensitivity (Kahneman and Tversky, 1979), they are more likely to embrace the gamble cooperation entails. Our subjects are also more prone to making strategic mistakes in the loss domain and, as we show, in high-risk social dilemmas, mistakes take the form of more cooperative play.

Our experimental game is the traveler's dilemma (henceforth TD), in which two players simultaneously submit claims that may take any value between a lower bound and an upper bound (Basu, 1994). Both players then receive the lower of the two submitted claims and a reward of size $R$ is paid to the player making the lower claim, while a penalty of size $R$ is deducted from the payoff of the player making the larger claim. Therefore, each player has an incentive to minimally undercut the other and in the unique Nash equilibrium both players claim the lower bound of the action space, regardless of the risk embodied in the size of the reward/penalty parameter $R$.

The TD captures the basic trade-off between what is privately and socially optimal that characterises our motivating examples. Yet, its simple payoff structure entails that it is easily explained to experimental subjects. Compared to its close relative, the prisoner's dilemma, it delivers a rich distribution of actions and thus facilitates estimating the structural model we use to get at the mechanism that drives our treatment effect. The TD is preferable to linear public good games because these lack the uncertainty about the marginal private returns to cooperation that characterises the real-world social dilemmas we seek to capture. At the same time, it is analytically simpler than step-level public good games that contain said uncertainty, but often feature multiple equilibria. 
We implement two main treatments. In the gain treatment admissible claims lie between 3 and 8 Euros. In the loss treatment subjects are given 11 Euros in cash for their participation at the beginning of the experiment and then stand to lose money, with admissible claims ranging from -8 to -3 Euros. In both treatments the reward/penalty parameter $R$ takes a value of 3 Euros and subjects play the game repeatedly, being anonymously matched with a new partner each time. The loss and gain treatments differ only in how payoffs are framed ${ }^{4}$ and would be equivalent if subjects were expected utility maximisers or if our framing did not have an impact on subjects' reference points or strategic sophistication.

We find large differences in the behaviour across our two treatments. In early periods, average claims in the loss treatment are up to 1.42 Euros or 42 percent higher than in the gain treatment. As learning sets in and strategic uncertainty is reduced, claims eventually converge to Nash play in both treatments. Therefore, the treatment effect is likely to arise in surprising, complicated or uncertain settings in which other agents' motivations and constraints are not perfectly understood, as would be the case in most markets or political systems and during crises.

As a preliminary step toward understanding the drivers of our treatment effect, we analyse analytically how best to play the TD in the presence of strategic uncertainty, which we model as stemming from an unsophisticated opponent who sometimes deviates from Nash play. ${ }^{5}$ We show that our treatment effect can be explained by subjects exhibiting either more risk tolerance, more altruism or a higher propensity to make mistakes in the loss domain.

Next, we consider the interaction between players of several different levels of sophistication in a cognitive hierarchy model (Camerer, Ho and Chong, 2004) that we augment to allow for, respectively, curvature in players' utility function and other-regarding preferences. Structural parameter estimates indicate that the experimental data is best matched by a model that supposes that subjects are either 1) more risk tolerant and 2) less sophisticated or $\hat{1}$ ) more altruistic and $\hat{2}$ ) less sophisticated when they make decisions in the loss domain. Both of these models

\footnotetext{
${ }^{4}$ Suppose, for example, player 1 chooses the fully cooperative action, which is 8 in the gain treatment and -3 in the loss treatment, and player 2 undercuts her by 0.1 . Then, in both the loss and the gain treatment, player 1 leaves the experiment with 4.9 Euros and player 2 with 10.9 Euros.

${ }^{5}$ In the absence of uncertainty, neither risk preferences nor plausible social preferences can explain cooperation in the TD. Noisy behaviour in the TD is also empirically plausible: Oppenheimer, Wendel and Frohlich (2011) find that from period to period, behaviour of many individuals in social dilemmas appears to be almost random. Furthermore, models premised on noisy decision making do well at explaining the effect of changing the reward/penalty parameter on subjects' behaviour in the TD (Capra et al., 1999).
} 
provide a better fit to the data than a model based solely on differences in strategic sophistication.

Finally, we make use of the fact that we elicit subjects' risk and social preferences as well as their propensity to make mistakes in strategic reasoning. We find that risk tolerance and propensity to make mistakes are higher in the loss domain. In the first test of gain-loss asymmetries in social preferences we are aware of, we find that dictator game giving is not responsive to the gain-loss frame. Furthermore, within subject correlations of preferences, sophistication and strategic behaviour suggest that a higher risk tolerance and propensity to make mistakes, but not dictator game giving, are associated with higher claims in the TD for the average subject. Therefore, treatment effects on individually elicited preference and measures of sophistication as well as within subject correlations of said variables with strategic behaviour suggest that reference-dependent risk preferences and referencedependent strategic sophistication, but not reference-dependent social preferences, drive cooperation in the loss domain. Suggestive evidence from a questionnaire after the experiment corroborates this explanation.

We introduce two additional treatments to test the scope of our risk- and noisebased explanation. In the gain-loss treatment both gains and losses are possible. We find that subjects' behaviour exhibits a form of loss avoidance (Cachon and Camerer, 1996): subjects predominantly choose the action that minimises their risk of loosing money. In line with our explanation of behaviour in the two main treatments, the utility function we estimate in the gain-loss treatment has the Sshape implied by diminishing sensitivity and its steepest gradient, i.e. its implied reference point, at the experimentally induced reference point.

In a further treatment we set the reward/punishment parameter to 0.5. Compared to the case of $R=3$, we find higher cooperation in both the loss and the gain domain. Moreover, when $R=0.5$, subjects cooperate slightly more in the gain than in the loss domain. This is consistent with our main results. Out-of-sample predictions of a cognitive hierarchy model that is parametrised using the data from the $R=3$ treatments match the empirical means of this low-risk treatment. Naturally, risk preferences matter less in low-risk situations and mistakes imply less cooperation when high cooperativeness is privately optimal for sophisticated players.

This paper makes two main contributions. First, it corroborates suggestive evidence from the field that the prospect of losses causes economic agents to cooperate, while ruling out explanations that do not rely on the gain-loss frame. Second, it uncovers the mechanism behind this treatment effect: reference-dependent strategic 
sophistication and reference-dependent risk preferences.

In the following section we relate our paper to the broader experimental literature. In section 3, we describe our experimental design and results. Section 4 is concerned with understanding the drivers of our treatment effect. Further treatments, in section 5, show that our explanation can account for changes in subjects' behaviour that occur once we alter the strategic environment. Section 6 concludes and highlights some policy implications.

\section{Related experimental literature}

Some studies in experimental economics compare subjects' propensity to contribute to public goods to their propensity to take from common resources (see Fosgaard, Hansen and Wengström (2014) or Cox (2015) for a list of papers in this literature). ${ }^{6}$ In these experiments, strategically equivalent public good games are presented to subjects under either a giving frame (public good) or a taking frame (common resource). The latter may conceivably also evoke a loss frame if subjects integrate the common resource into their wealth. ${ }^{7}$ Evidence is mixed, with several studies finding higher contributions under the giving frame and several other studies, including a large sample experiment by Fosgaard, Hansen and Wengström (2014), finding the opposite. Our paper differs along two dimensions from these experiments and we do not take a strong stand on their findings. First, in line with our motivating examples, we do not vary the moral frame on subjects' action space, but rather attempt to vary the reference point of their payoff function. Second, the linear public good games typically featured in the above experiments have a dominant strategy. To capture the inherent riskiness of our motivating examples, our game does not. If agents are self-interested, a dominant strategy implies that risk preferences should not impact on behaviour.

Iturbe-Ormaetxe et al. (2011) study a public good game without a dominant strategy, in which the good is only provided if $k$ individuals contribute. Consistent with our results, they find that, when $k$ is equal to the group size, framing the public good game as a game of taking from a common resource increases contributions. These findings can be rationalised not only by loss aversion, as the authors show,

\footnotetext{
${ }^{6}$ In the field, Ostrom (1990) argues that groups frequently overcome individual incentives to exploit open access common pool resources such as forests and fisheries, especially when appropriators are very dependent on the resource and its risk of depletion is high (Ostrom, 2000).

${ }^{7}$ See Cox (2015) for a discussion of how take/give and gain/loss frames may be confounded in some of these studies.
} 
but also by diminishing sensitivity. In their game, the benefit of consuming a public good outweighs the cost of contributing. When the whole group needs to contribute for the public good to be created, contributing is risky in that it yields the public good minus the cost of contributing if everybody else is contributing and only costs if at least one person fails to contribute. Not contributing, on the other hand, is safe and yields zero payoffs with certainty. As a result, we expect more contributions under a taking or loss frame that makes subjects are more risk tolerant. ${ }^{8}$

Some experiments in psychology compare prisoner's dilemma play in the gain and loss domain, but no clear treatment effect emerges (see De Dreu and McCusker (1997) and De Heus, Hoogervorst and Van Dijk (2010) for reviews of the evidence). Similar to the linear public good game, the prisoner's dilemma has a dominant strategy and risk preferences are irrelevant if a player is self-interested. Interestingly, however, De Dreu and McCusker (1997) find that individuals they characterise as collaborators do in fact cooperate more in the loss domain. This is in line with our findings. An individual with sufficiently strong social preferences like inequity aversion, for example, obtains the highest utility from both parties cooperating, while cooperating and being defected upon constitutes the worst-case scenario. When there is strategic uncertainty, defecting is therefore not a dominant strategy for collaborators and risk preferences matter in determining their favoured action much like they do in the TD. Also consistent with this, Mengel (2014) finds evidence that the downside risk of cooperating is the most important driver of cooperation in prisoner's dilemmas with random matching.

In a two-player game of chicken, player 1's preference ordering over outcomes is given by (defect, cooperate) $\succ$ (cooperate, cooperate) $\succ$ (cooperate, defect) $\succ$ (defect, defect). De Heus, Hoogervorst and Van Dijk (2010) find that individuals cooperate less when they play the game of chicken in the loss domain. They argue that the payoff structure of the game implies that defecting is the high-potentialreward and high-variance action and that subjects defect more frequently in the loss domain because of diminishing sensitivity. Their findings lend support to our risk-preference based explanation and highlight the importance of a game's exact payoff structure in shaping gain-loss differences in strategic behaviour. The chicken game is also a social dilemma, but the TD's assumption that (defect, defect) $\succ$ (cooperate, defect) better fits our motivating examples.

\footnotetext{
${ }^{8}$ When $k=1$, subjects in Iturbe-Ormaetxe et al. (2011) contribute less under the taking or loss frame. Of course, when a single contribution is enough to create the public good, not contributing becomes the high variance action and higher risk tolerance implies a lower likelihood of contributing.
} 
The TD can be taken to capture a setting of imperfect price competition between two firms with differentiated products or capacity constraints. ${ }^{9}$ The effect of the loss treatment then captures the anticompetitive effects of sunk costs or bad demand conditions. Offerman and Potters (2006) find that auctioning off entry fees or imposing fixed sunk costs in a Bertrand oligopoly increases collusion among experimental entrants, Kachelmeier (1996) finds that sunk costs have no effect in a double auction and Buchheit and Feltovich (2011) find that experimental market prices are first increasing and then decreasing in sunk costs. Our experiment differs in that it is simpler and explicitly designed to induce losses and uncover the mechanism behind our treatment effect.

Previous experiments featuring the TD show that for low values of $R$ relative to the upper bound, claims are clustered around the highest possible claim (Capra et al., 1999; Goeree and Holt, 2001; Becker, Carter and Naeve, 2005; Rubinstein, 2007), a result we replicate in section 5.2. As the reward/penalty parameter grows larger, however, claims converge to the Nash equilibrium play (Capra et al., 1999; Goeree and Holt, 2001). This comparative static in $R$ is well explained by models of noisy decision making (Capra et al., 1999) and models of strategic uncertainty (Baghestanian, 2014), suggesting that, as we assume, uncertainty plays a key role in driving behaviour in the TD. These previous experiments also helped us calibrate our experimental game and rendered a pilot unnecessary.

We explain our treatment effect by asserting that subjects are less risk averse and less sophisticated in the loss domain. Diminishing sensitivity (Kahneman and Tversky, 1979), has been documented in the decision making of experimental subjects and the general population (Booij, Praag and van de Kuilen, 2010; Tymula et al., 2012). In a review of studies that estimate the curvature of individuals' utility functions in the gain and loss domain 9 out of 11 studies find risk loving preferences in the loss domain and risk aversion in the gain domain (Booij, Praag and van de Kuilen, 2010). Camerer (2003) provides some examples from the field. However, our explanation is based on a weaker condition than diminishing sensitivity: we merely require that individuals are less risk averse in the loss domain.

In line with our result on subjects' sophistication, Tymula et al. (2012) find that in a sample of over 8000 individual choices, stochastic dominance violations in choices between simple lotteries and certain payoffs are more likely in the loss domain. In line with our result that dictator game giving is not correlated with

\footnotetext{
${ }^{9}$ See Capra et al. (2002) for an experiment in which firms engage in Bertrand competition and the firm setting the higher price has a non-vanishing market share. In this case, the size of the residual market is the counterpart of the reward/penalty parameter in the TD.
} 
actions in the TD, Brañas-Garza, Espinosa and Rey-Biel (2011) document that pro-social considerations are absent from a subjects' ex-post explanation of the action they chose in a TD experiment.

\section{$3 \quad$ Experimental design and results}

\subsection{Design}

We let subjects in a computerised experiment play the traveler's dilemma, in which a player's payoff, if she claims $x_{i}$ and her opponent claims $x_{j}$, is given by

$$
\pi_{i}=\left\{\begin{array}{rll}
x_{i}+R & \text { if } & x_{i}<x_{j} \\
x_{j}-R & \text { if } & x_{i}>x_{j} \\
x_{i} & \text { if } & x_{i}=x_{j}
\end{array}\right.
$$

Subjects were randomly assigned to sessions belonging to either a gain or a loss treatment. In the gain treatment, subjects received no participation fee and admissible claims lay between 3 and 8 Euros. In the loss treatment, they received a participation fee of 11 Euros before the experiment and admissible claims lay between -8 and -3 Euros. Subjects then had to reimburse the experimenter for any losses they incurred. R was set equal to 3 Euros in both treatments.

In a first set of sessions, which we call experiment 1, subjects played the TD five times $^{10}$ and the action set was finely grained: any multiple of 0.1 Euros between the lower and upper bound of the claims range was admissible. In a second set of sessions, which we call experiment 2, we let subjects play the TD ten times and elicited risk preferences, social preferences and propensity to make mistakes in strategic reasoning. In experiment 2, we also wanted to check how results in experiment 1 extend to a coarser action set and thus restricted claims to be multiples 0.5 .

In both experiments, we paired each subject with a different person in each period to avoid dynamic strategic considerations and we used a randomly selected period to determine final earnings to avoid wealth effects. In experiment 2 , periods that featured preference elicitation tasks were also eligible to be selected for payment. The TD was introduced to subjects in its abstract form (see the instructions in appendix $\mathrm{C}$ ).

\footnotetext{
${ }^{10}$ They then played five more surprise periods that serve as a consistency check that we discuss in section 5.2.
} 


\section{Gain treatment}

Part A:

- no fee

- elicitation of risk preferences over gains

- 10 periods of the TD over gains

- elicitation of social preferences over gains.

Part B:

- $3 €$ fee

- quiz on the TD with a reward for correct answers

Part C: questionnaire

\section{Loss treatment}

Part A:

- $11 €$ fee

$\rightarrow$ elicitation of risk preferences over losses

- 10 periods of the TD over losses

- elicitation of social preferences over losses.

Part B:

- $9 €$ fee;

- quiz on the TD with a penalty for wrong answers

Part C: questionnaire

Table 1 The sequencing of tasks in experiment 2

We conducted a total of twelve experimental sessions at the Toulouse School of Economics experimental laboratory with student subjects. ${ }^{11}$ The experiment was programmed on z-Tree (Fischbacher, 2007).

Experiment 1 was designed to demonstrate the treatment effect in a clean fashion, without contamination or excessive cognitive load from other tasks. Experiment 2 serves to investigate the drivers of the treatment effect we observe. It also provides a view of how play evolves in later periods.

Table 1 depicts the design of experiment 2. The dashed arrows indicate that we switched the timing of risk and social preference elicitation in half of the sessions, in order to detect potential order effects. Payoffs from preference elicitation periods were only revealed at the end of part A. Part B of the experiment came as a surprise and subjects were paid for it separately.

Risk preferences. We elicited risk preferences by letting subjects choose between different lotteries, as in Holt and Laury (2002) (see table 7 in appendix B). Outcomes of lotteries in the loss treatment were 11 Euro less than those in the gain treatment and thereby fully embedded in the loss domain. The HL switching point refers to the least favourable pair of lotteries for which a subject prefers the riskier

\footnotetext{
${ }^{11}$ Experiment 1 featured two sessions under the gain treatment (34 subjects), two under the loss treatment (32 subjects) and two under the gain-loss treatment (34 subjects) described in section 5.1. Sessions lasted less than 30 minutes and subjects earned on average 6.30 Euros. Experiment 2 featured three sessions under the gain treatment (36 subjects) and three under the loss treatment (42 subjects). Sessions lasted 45 minutes and subjects earned on average 9.80 Euros.
} 
one. It is increasing in risk aversion. As a second non-strategic risk preferences elicitation task, we let subjects play the TD of the corresponding treatment against the computer, which was programmed to choose each claim with equal probability. The more risk averse a subject is, the lower her risk TD claim should be.

Social preferences. To elicit social preferences, we paired each subject with a randomly selected anonymous partner. ${ }^{12}$ In a dictator game (see table 8 in appendix B), dictators in the gain treatment had to choose how to split 8 Euros with their partners, while dictators in the loss treatment had to choose how to allocate a loss of 8 Euros. The more prosocial a subject is, the higher her dictator giving should be, i.e. the higher the dictator game payoff she allocates to her partner. As in the risk preference elicitation, each subject also played the TD of her corresponding treatment against a computer that randomly chose claims. This time, however, the computer's payoff went to the subject's partner. The difference between choices in this task, which we denote by social TD claim, and the risk TD claim provides another measure of prosociality.

Mistakes and strategic sophistication. In part B of experiment 2 we elicited subjects' strategic sophistication by presenting them with a quiz featuring 8 questions of varying degrees of difficulty, ranging from simple questions on the payoff structure to more advanced questions on optimal actions conditional on an opponent's behaviour. Hypothetical payoffs and actions in the quiz were framed according to the treatment the subject was in. Furthermore, subjects in the gain treatment earned 0.5 Euros for a correct answer, while subjects in the loss treatment lost 0.5 Euros for a wrong answer. The quiz thus captured the effect of incentivising subjects through losses as well as the difficulty subjects may experience in thinking in terms of losses. We also elicited subjects' beliefs about their own and others' performance in the quiz, while providing incentives for accuracy as high as 2 Euros. The initial fees for part B were 3 and 9 Euros in the gain and loss treatment respectively. ${ }^{13}$

Part $\mathrm{C}$ consisted of a questionnaire on the motives behind subjects' choices in the TD (see tables 10 and 11 in appendix B).

\footnotetext{
${ }^{12}$ In order to provide proper incentives without losing observations, each subject performed all social preference elicitation tasks. Then, with equal probability, either her choice or that of her partner determined earnings for the period.

${ }^{13}$ The fees are such that a given number of correct answers yields identical earnings in the two treatments.
} 


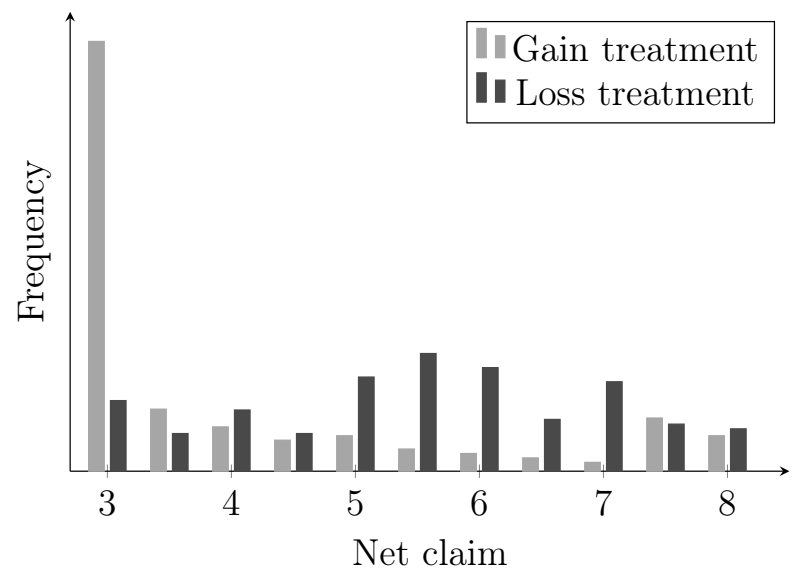

(a) Distribution of claims

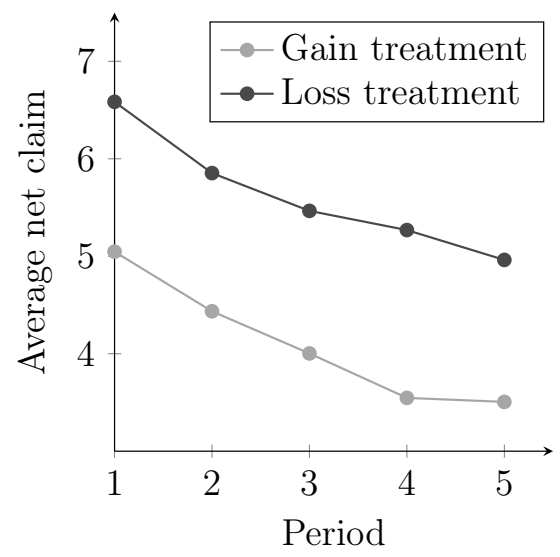

(b) Average claims per period

Figure 1 The treatment effect in experiment 1

\subsection{The treatment effect}

Figure 1a depicts the gain and loss treatments' distributions of claims, pooling all 5 periods of experiment 1 . For the sake of comparability, we present results in terms of net claims, which obtain by adding the participation fee of the corresponding treatment to actual claims. ${ }^{14}$ The distribution in the gain treatment has most of its mass concentrated around the Nash equilibrium at 3, while the distribution in the loss treatment is more dispersed, with a single peak around the centre of the action set and a higher mean. The mass around the most cooperative action (i.e. $8)$ is similar in both treatments.

Figure $1 \mathrm{~b}$ shows average claims per period. In all periods, claims are higher in the loss treatment than in the gain treatment and this difference is significant at the 1 percent level according to both a t-test and a Wilcoxon rank sum test. In period 5, the average claim is 3.51 Euros in the gain treatment and 4.96 Euros in the loss treatment. Framing payoffs as losses therefore increases cooperation by up to 41 percent.

Our results also indicate that subjects' behaviour departs substantially from Nash equilibrium, especially in the loss treatment. They are therefore inconsistent with the assumption of fully rational players.

\footnotetext{
${ }^{14}$ That is, we translate claims in the loss treatment to claims into the action space of the gain treatment by adding 11 Euros.
} 


\section{Explaining the treatment effect}

\subsection{A stylised model of strategic uncertainty}

To gain an intuition for how bounded rationality, risk preferences and social preferences may shape behaviour in the TD, it is useful to transform the game into a non-strategic decision problem. ${ }^{15}$ Suppose that player 1, a rational agent, is playing the TD with player 2, a non-strategic opponent, who plays the Nash equilibrium strategy $x_{2}=3$ with probability $(1-p) \in[0,1]$ and $x_{2}=m+0.1$ with complementary probability, where $m>3 .{ }^{16}$ We may interpret $p$ as the probability of a mistake and $m$ as its size, so that both $p$ and $m$ are measures of player 2's lack of sophistication.

Assume first that player 1 is self-interested and that her utility is given by $U\left(z_{1}\right)$, where $z_{1}$ represents her material payoff and $U^{\prime}\left(z_{1}\right)>0$. Faced with player 2 , player 1 then only has two sensible choices: she may either play her Nash strategy $x_{1}=3$, or she may try to capitalise on player 2's mistake by minimally undercutting, i.e. by playing $x_{1}=m$. Given the payoff structure of the TD, player 1 finds it optimal to play $x_{1}=m$ if and only if

$$
(1-p) U(3-R)+p U(m+R)>(1-p) U(3)+p U(3+R) .
$$

When player 1 plays $x_{1}=m$ instead of $x_{1}=3$, she risks being undercut in situations in which player 2 does not make a mistake. This downside risk associated with moving away from the Nash outcome is a key feature of the social dilemmas in the uncertain environments we outline in the introduction. ${ }^{17}$ Crucially, the spread of payoffs is higher on the left-hand side of equation (1) than on the right-hand side: the minimum and maximum payoffs from playing $x_{1}=m$ are respectively lower and higher than the minimum and maximum payoffs from playing $x_{1}=3$. Player 1 therefore has to decide between two gambles with equal probabilities but different variances. A risk loving player 1 is more comfortable with a higher variance in payoffs and thus more comfortable with playing $x_{1}=m$ than a risk averse

\footnotetext{
${ }^{15}$ The more elaborate model we adopt in the next section cannot be solved for analytically, which makes getting at the intuition behind comparative statics harder.

${ }^{16}$ Without loss of generality we are implicitly assuming here that the TD is played with the fine action set.

${ }^{17}$ The downside risk would also be present if player 1 was choosing whether to defect or cooperate in a prisoners' dilemma. However, contrary to the TD, in a prisoner's dilemma, cooperating never yields higher utility for a self-interested individual. For a sufficiently altruistic individual, on the other hand, (cooperate, cooperate) may be the favoured prisoners' dilemma outcome.
} 
individual.

We define a risk averse, a risk neutral and a risk loving individual as an individual whose utility function is characterised by $U^{\prime \prime}\left(z_{1}\right)<0, U^{\prime \prime}\left(z_{1}\right)=0$ and $U^{\prime \prime}\left(z_{1}\right)>0$ respectively and we index them by $a, n$ and $l$. The following proposition (all proofs for this section can be found in appendix A) then establishes more formally the above intuition, as well as that cooperating is more attractive when mistakes on behalf of player 2 are large and frequent.

Proposition 1. There exists a unique threshold $p^{*} \in(0,1)$ such that

- player 1 claims $x_{1}=m$ if and only if $p>p^{*}$ and $x_{1}=3$ otherwise;

- $p^{*}$ is decreasing in $m$;

- $p^{*}$ is lower for a risk loving than for a risk neutral individual and higher for a risk averse than for a risk neutral individual, i.e. $p_{l}^{*}<p_{n}^{*}<p_{a}^{*}$.

Let us now assume risk neutrality and allow for social preferences on behalf of player 1. In particular, suppose that the utility of player 1 takes the form of $U\left(z_{1} ; z_{2}\right)=z_{1}+\beta z_{2}$, where $z_{2}$ is the material payoff of player 2 and $\beta \in(0,1)$ a measure of player 1's altruism. ${ }^{18}$ The following proposition shows that altruism, like risk lovingness, provides an incentive for player 1 to deviate from Nash play and that this incentive is stronger the less sophisticated player 2 is:

Proposition 2. There exists a unique threshold $p_{\beta}^{*} \in(0,1)$ such that

- player 1 deviates from $x_{1}=3$ if and only if $p>p_{\beta}^{*}$;

- $p_{\beta}^{*}$ is decreasing in $m$ and $\beta$.

Propositions 1 and 2 tell us that changes in risk preferences and altruism can systematically impact on subjects' tendency to cooperate in a TD with underlying uncertainty. Since we observe that individuals cooperate more in the loss domain, the propositions imply that the treatment effect could be accounted for by higher levels of risk lovingness or altruism in the loss domain. Of course, a higher propensity to make mistakes, as reflected in a higher $p$, or larger mistakes, as reflected in a larger $m$, would also lead to more frequent deviations from Nash. In this stylised example, player 2 does not react strategically to player 1's actions. The next section demonstrates that the simple intuitions developed here have bite when we allow for a larger set of strategic types.

\footnotetext{
${ }^{18}$ We model prosocial considerations in the simplest possible way, but results generalise to other other-regarding preferences. For instance, if player 1's utility is as in Fehr and Schmidt (1999), similar predictions obtain based on her aversion to advantageous inequality.
} 


\subsection{Estimates from a cognitive hierarchy model}

The structural estimations of this section can be viewed as a comparative statics exercise that maps the experimental data from our two treatments into implied differences in risk preferences, social preferences and sophistication. Results indicate that an explanation based on less sophistication in the loss domain alone does a bad job at explaining the treatment effect, but they do not allow us to distinguish between explanations that feature either reference-dependent risk preferences and reference-dependent sophistication or reference-dependent social preferences and reference-dependent sophistication.

We adopt an augmented version of the cognitive hierarchy model in Camerer, Ho and Chong (2004). Subjects belong to different steps of sophistication, indexed by an integer $k$. Steps in the population follow a Poisson distribution parametrised by $t$, both the distribution's mean and variance. Each step $k>0$ player myopically believes to be the most sophisticated player and, in particular, that the distribution of other players follows a Poisson distribution parametrised by $t$, but right-truncated at $k-1$. A step $k>0$ player's belief about the frequency of step $h<k$ players is thus given by

$$
g_{k}(h)=\frac{\frac{e^{-t} t^{h}}{h !}}{\sum_{l=0}^{k-1} \frac{e^{-t} t^{l}}{l !}} .
$$

Each step $k>0$ player maximises her expected utility $U^{e}(x)$ given her beliefs specified in (2) and anticipating that each step $h<k$ behaves in a similar fashion. The model solves recursively after specifying the behaviour of step 0 players. We assume that a fraction $1-w$ of step 0 players randomise over the action set, while the remaining fraction $w$ play the highest action. ${ }^{19}$

With the exception of Goeree, Holt and Palfrey (2002) and Goeree, Holt and Palfrey (2003), experimental papers that make use of models of noisy strategic interactions impose that players are risk neutral and selfish. In order to capture risk attitudes, we adopt the more general functional form $U\left(z_{1}\right)=z_{1}^{\alpha}$, where $z_{1}$ represents a player's material payoff. ${ }^{20}$ Then, $\alpha<1, \alpha=1$ and $\alpha>1$ respectively capture risk aversion, neutrality and lovingness. We also consider an alternative model with altruism, in which utility takes the form $U\left(z_{1} ; z_{1}\right)=z_{1}+\beta z_{2}$, where $z_{2}$ is the material payoff of the other player.

\footnotetext{
${ }^{19}$ Arad and Rubinstein (2012) adopt a similar specification for the behaviour of level 0 players in a game which bears some similarities with the TD. Qualitative results are robust to imposing that $w=0$.

${ }^{20} \mathrm{As}$ we run all estimations using net claims, there is no need to define $U\left(z_{1}\right)$ piecewise for the gain and the loss domain.
} 
Both models have three parameters, respectively $(t, w, \alpha)$ and $(t, w, \beta)$, and solve numerically for any parameter values. Using maximum likelihood techniques, we determine which combination of parameters best replicates the observed distribution of our subjects' actions in each period. The trends in figure $1 \mathrm{~b}$ might be interpreted as evidence of learning as play progresses, which in the models would translate into higher values of $t$ and lower values of $w$. Conversely, there is no a priori reason to expect $\alpha$ or $\beta$ to change across periods. We therefore also estimate each model jointly over the five periods under the respective restriction that $\alpha$ or $\beta$ remain constant.

Table 2 reports estimates of the model that allows for different risk preferences. Estimates of $\alpha$ confirm the link between risk preferences on cooperation established in section 4.1. ${ }^{21}$ For instance, in the joint model we obtain $\hat{\alpha}=0.95$ in the gain treatment and $\hat{\alpha}=3.25$ in the loss treatment. We use a likelihood ratio test that compares these models with a model that imposes the risk-neutrality restriction $(\alpha=1)$ to check whether estimates of $\alpha$ are significantly different from 1 . In the loss treatment we are able to reject risk-neutrality in favour of risk-lovingness at the 1 percent significance level. In the gain treatment we cannot reject risk neutrality. These results are confirmed in the models that are estimated over individual periods. Thus, the model that best matches the observed distribution of actions is one that supposes individuals are more risk tolerant in the loss domain.

Estimates of $t$ suggest that the average subject is also less sophisticated in the loss domain. ${ }^{22}$ But the likelihood ratio test on the restriction of risk neutrality

\footnotetext{
${ }^{21}$ One can show numerically that the optimal action of a step 1 player (and hence of all more sophisticated players) is weakly increasing in $\alpha$ and coincides with Nash play when $\alpha$ is lower than some cutoff $\bar{\alpha}(w)$, where $\bar{\alpha}(w)$ is decreasing in $w$ and $\bar{\alpha}(0)=\frac{6}{5}$. When the likelihood attains the maximum in the $\alpha<\bar{\alpha}$ region, in case of multiple maximizers we adopt the convention to select the largest $\alpha$.

${ }^{22}$ Overall, values of $t$ are a slightly smaller than typical estimates from the literature. This is due to the fact that the action set is large, play is fairly dispersed and $k>0$ players overall use only a small set of actions. Thus, the model attributes actions outside this set to step 0 players. To control for this feature, we also estimated a variation of the cognitive hierarchy model that allows for noisy optimising behaviour, similarly to Lim, Matros and Turoc (2014). That is, a logistic decision rule specifies that given her beliefs, a level $k>0$ player chooses each action $x$ in her action set $X$ with probability

$$
P(x)=\frac{\exp \left(\frac{U^{e}(x)}{\mu}\right)}{\sum_{q \in X} \exp \left(\frac{U^{e}(q)}{\mu}\right)},
$$

where $\mu$ is a parameter that measures the sensitivity of choice probabilities to payoffs. This models yields higher estimates of $t$ in both treatments. We report results from the standard model because it yields qualitatively similar results and is computationally less burdensome. Besides, under noisy optimising behaviour, we need to make additional restrictions to separately identify risk and noise
} 
Table 2 Estimates of risk preferences in a cognitive hierarchy model

\begin{tabular}{|c|c|c|c|c|c|c|}
\hline Treatment & Period & Restriction & $\alpha$ & $t$ & $w$ & $\log L$ \\
\hline \multirow[t]{6}{*}{ Gain } & 1 & None & $\begin{array}{c}0.95 \\
(0.12)\end{array}$ & $\begin{array}{c}0.31 \\
(0.102)\end{array}$ & $\begin{array}{c}0.2 \\
(0.09)\end{array}$ & -110.038 \\
\hline & 2 & None & $\begin{array}{c}1.1 \\
(0.062)\end{array}$ & $\begin{array}{c}0.51 \\
(0.155)\end{array}$ & $\begin{array}{c}0.06 \\
(0.059)\end{array}$ & -99.640 \\
\hline & 3 & None & $\begin{array}{c}1.15 \\
(0.034)\end{array}$ & $\begin{array}{c}0.56 \\
(0.156)\end{array}$ & $\begin{array}{c}0.01 \\
0.034\end{array}$ & -94.173 \\
\hline & 4 & None & $\begin{array}{c}1.15 \\
(0.034)\end{array}$ & $\begin{array}{c}0.9 \\
(0.222)\end{array}$ & $\begin{array}{c}0.01 \\
(0.034)\end{array}$ & -77.958 \\
\hline & 5 & None & $\begin{array}{c}1.05 \\
(0.123)\end{array}$ & $\begin{array}{c}1.3 \\
(0.268)\end{array}$ & $\begin{array}{c}0.11 \\
(0.101)\end{array}$ & -53.938 \\
\hline & all 5 & $\alpha$ const & 0.95 & & & -435.75 \\
\hline \multirow[t]{6}{*}{ Loss } & 1 & None & $\begin{array}{c}6^{* * *} \\
(1.716)\end{array}$ & $\begin{array}{c}0.11 \\
(0.065)\end{array}$ & $\begin{array}{c}0.11 \\
(0.062)\end{array}$ & -117.161 \\
\hline & 2 & None & $\begin{array}{l}2.3^{* * *} \\
(0.678)\end{array}$ & $\begin{array}{c}0.16 \\
(0.082)\end{array}$ & $\begin{array}{c}0.06 \\
(0.054)\end{array}$ & -118.671 \\
\hline & & None & $\begin{array}{c}4.0^{* * *} \\
(0.56)\end{array}$ & $\begin{array}{c}0.26 \\
(0.113)\end{array}$ & $\begin{array}{c}0.06 \\
(0.053)\end{array}$ & -119.08 \\
\hline & 4 & None & $\begin{array}{c}3.25^{* * *} \\
(0.434)\end{array}$ & $\begin{array}{c}0.21 \\
(0.094)\end{array}$ & $\begin{array}{c}0.01 \\
(0.027)\end{array}$ & -116.868 \\
\hline & 5 & None & $\begin{array}{c}1.5 \\
(0.88)\end{array}$ & $\begin{array}{c}0.16 \\
(0.084)\end{array}$ & $\begin{array}{c}0.06 \\
(0.039)\end{array}$ & -121.53 \\
\hline & all 5 & $\alpha$ const & $3.25^{* * *}$ & & & -609.095 \\
\hline
\end{tabular}

Note: Bootstrapped standard errors in parentheses; significance levels from a likelihoodratio test against the restriction $\alpha=1$ : * $(p<0.1)$, ** $(p<0.05),{ }^{* * *}(p<0.01)$.

implies that risk-preferences in combination with sophistication fares better at explaining our treatment effect than an explanation based on less sophistication in the loss domain alone. Note also that estimates of $t$ show a clear increasing pattern over periods in the gain treatment but less so in the loss treatment, while estimates of $w$ tend to decrease in both treatments.

Table 3 presents estimates of the model that allows for altruism. Estimates confirm the prediction of section 4.1 that more altruism in the loss domain can also explain our treatment effect. Moreover, the log-likelihoods of the models featuring risk preferences and the models featuring altruism are very similar. A socialpreference based explanation thus fits the aggregate data just as well as a risk-based explanation.

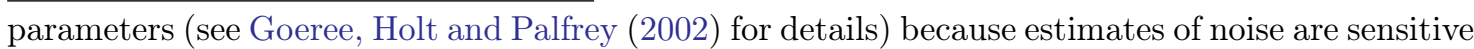
to the scale of payoffs. 
Table 3 Estimates of altruism in a cognitive hierarchy model

\begin{tabular}{|c|c|c|c|c|c|c|}
\hline Treatment & Period & Restriction & $\beta$ & $t$ & $w$ & $\log L$ \\
\hline \multirow[t]{6}{*}{ Gain } & 1 & None & $\begin{array}{c}0 \\
(0.02)\end{array}$ & $\begin{array}{c}0.31 \\
(0.103)\end{array}$ & $\begin{array}{c}0.15 \\
(0.04)\end{array}$ & -110.092 \\
\hline & 2 & None & $\begin{array}{c}0.05 \\
(0.024)\end{array}$ & $\begin{array}{c}0.51 \\
(0.15)\end{array}$ & $\begin{array}{c}0.075 \\
0.052)\end{array}$ & -99.592 \\
\hline & 3 & None & $\begin{array}{c}0.05 \\
(0.007)\end{array}$ & $\begin{array}{c}0.61 \\
(0.172)\end{array}$ & $\begin{array}{c}0 \\
(0.025)\end{array}$ & -93.925 \\
\hline & 4 & None & $\begin{array}{c}0.05 \\
(0.029)\end{array}$ & $\begin{array}{c}0.86 \\
(0.233)\end{array}$ & $\begin{array}{c}0 \\
(0.031)\end{array}$ & -77.803 \\
\hline & 5 & None & $\begin{array}{c}0 \\
(0.025)\end{array}$ & $\begin{array}{c}1.31 \\
(0.34)\end{array}$ & $\begin{array}{c}0.1 \\
(0.063)\end{array}$ & -53.926 \\
\hline & all 5 & $\beta$ const & 0 & & & -435.34 \\
\hline \multirow[t]{6}{*}{ Loss } & 1 & None & $\begin{array}{l}0.9 * * * \\
(0.273)\end{array}$ & $\begin{array}{c}0.11 \\
(0.061)\end{array}$ & $\begin{array}{c}0.1 \\
(0.064)\end{array}$ & -117.015 \\
\hline & 2 & None & $\begin{array}{l}0.3 * * * \\
(0.121)\end{array}$ & $\begin{array}{c}0.15 \\
(0.08)\end{array}$ & $\begin{array}{l}0.025 \\
(0.03)\end{array}$ & -118.856 \\
\hline & 3 & None & $\begin{array}{c}0.35 * * * \\
(0.059)\end{array}$ & $\begin{array}{c}0.26 \\
(0.109)\end{array}$ & $\begin{array}{c}0.15 \\
(0.052)\end{array}$ & -120 \\
\hline & 4 & None & $\begin{array}{l}0.4^{* * *} \\
(0.068)\end{array}$ & $\begin{array}{c}0.21 \\
(0.096)\end{array}$ & $\begin{array}{c}0 \\
(0.011)\end{array}$ & -117.022 \\
\hline & 5 & None & $\begin{array}{c}0.05 \\
(0.239)\end{array}$ & $\begin{array}{c}0.11 \\
(0.052)\end{array}$ & $\begin{array}{c}0 \\
(0.022)\end{array}$ & -121.595 \\
\hline & all 5 & $\beta$ const & $0.4^{* * *}$ & & & -605.911 \\
\hline
\end{tabular}

Note: Bootstrapped standard errors in parentheses; significance levels from a likelihoodratio test against the restriction $\beta=0:{ }^{*}(p<0.1),{ }^{* *}(p<0.05),{ }^{* * *}(p<0.01)$.

\subsection{Determinants of the treatment effect}

\subsubsection{The treatment effect on strategic behaviour in experiment 2}

We designed experiment 2 to measure social preferences, risk preferences and sophistication directly. This allows us to better identify the drivers of our treatment effect by checking for treatment effects on these variables and by looking at within subject correlations between preferences, mistakes and strategic behaviour. By adding three more sessions in each treatment, experiment 2 also increases the statistical power behind our statement that TD play is more cooperative in the loss domain.

Figure 2 depicts average net claims in experiments 1 and 2 across periods and by treatment. In experiment 2, claims are significantly higher in the loss treatment in every period except for the last two. According to a Wilcoxon rank sum test, 


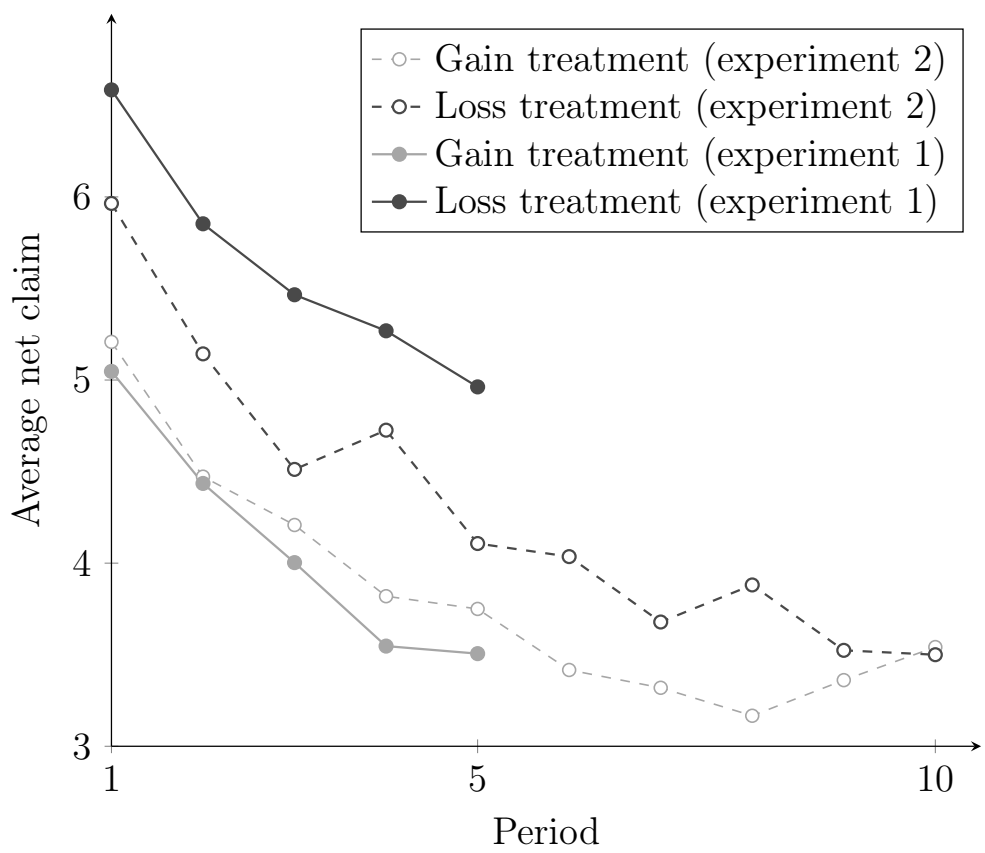

Figure 2 Average claims per period in experiment 2

the treatment difference in claims in each of the the first eight periods is significant at the 5 percent level, except in period 3, where it is significant at the 10 percent level.

At the same time, the treatment effect on strategic behaviour is smaller in experiment 2 than in experiment 1. Our favoured explanation for this is the coarser action set of experiment 2 (11 instead of 51 actions). A subject who plans to minimally undercut her opponent in experiment 2 mechanically has to choose a lower claim than a subject in experiment $1 .^{23}$ Alternatively, the preference elicitation tasks that preceded the 10 periods of TD play may contribute to the smaller treatment effect by influencing a subject's expectation about her opponent's behaviour.

Experiment 2 also allows us to observe TD play after 5 periods. In the final periods of the experiment we observe convergence to Nash equilibrium play in both treatments. Capra et al. (1999) explain this decreasing pattern of claims by alluding to a process of learning. As subjects start to better predict their opponent's action or modify their behaviour on the basis of negative and positive reinforcement, play evolves towards the Nash action. As uncertainty decreases, risk preferences too are likely to play a less important role. Comparing earlier and later periods therefore nicely demonstrates that our treatment effect and theory are likely to be more

\footnotetext{
${ }^{23}$ This effect of coarseness is consistent with the logic of cognitive hierarchy models, in which players undercut each other in ascending order of sophistication. A quantal response equilibrium model, as in Capra et al. (1999), cannot directly account for this effect.
} 
pertinent in noisy and uncertain settings. Arguably, most real world social dilemmas take place in precisely such environments.

\subsubsection{Treatment effects on preferences and mistakes}

The individual decision making tasks of experiment 2 help us further identify the most plausible mechanism underlying our treatment effect. For either risk preferences, social preferences or sophistication to constitute a valid part of the explanation of our treatment effect, the variable in question, when measured directly, should respond to the loss treatment in the expected way.

Table 4 tells us whether preferences and the propensity to make mistakes exhibit treatment effects. The first four rows of the table feature the switching points in a Holt and Laury (2002) lottery choice list. Over the full sample, a t-test indicates that individuals are significantly more risk averse in the gain domain. The pattern persists in row 2, where we only consider subjects for whom risk preferences were elicited before the TD was played. Rows 3 and 4 exclude those subjects that did not switch within the ten options of the HL lottery, thereby revealing themselves to irrationally preferring a sure 6 Euros to a sure 10.5 Euros. Subjects again exhibit more risk aversion in the gain domain, although this difference falls just short of being significant at the 10 percent level when we only consider risk preferences elicited in the first period. But since HL switching points do not exhibit order effects (see table 9 in appendix B), we can safely consider the whole sample.

Rows 5 and 6 of table 4 provide the first test of the impact of gain/loss frames on social preferences we are aware of: subjects playing a dictator game do not give significantly more in the loss compared to the gain domain. Row 7 indicates that subjects do significantly better in a quiz about optimal play in the TD, when they are paid with gains rather than penalised by losses and payoffs in the quiz are framed as gains rather than losses.

When we transform the TD into an individual decision making task in which subjects play against a computer who picks a claim at random, subjects make considerably more risk averse choices in the gain domain. Adding a social component by giving the computer player's payoffs to another subject does not significantly increase the difference in behaviour between the gain and loss domain. This is made precise in the last two rows of table 4 . To summarise, there is a treatment effect on risk preferences and the propensity to make mistakes, as captured by the quiz, but not on social preferences. 
Table 4 Elicited preferences and propensity to make mistakes

\begin{tabular}{lcccccc}
\hline \hline & & \multicolumn{6}{c}{ Gains } & \multicolumn{3}{c}{ Losses } \\
& Sample & Mean & $\mathrm{N}$ & Mean & $\mathrm{N}$ & Difference \\
\hline \multirow{2}{*}{ HL switching point } & full & 6.83 & 36 & 5.95 & 42 & $0.88^{* *}$ \\
& first round & 6.72 & 18 & 5.62 & 21 & $1.10^{*}$ \\
HL switching point $(<11)$ & full & 6.31 & 32 & 5.56 & 39 & $0.75^{* *}$ \\
& first round & 6.19 & 16 & 5.35 & 20 & 0.84 \\
Dictator giving & full & 3.14 & 36 & 3.21 & 42 & -0.07 \\
& first round & 3.17 & 18 & 3.62 & 21 & -0.45 \\
Quiz score & full & 5.89 & 36 & 4.21 & 42 & $1.67^{* * *}$ \\
Risk TD claim & full & 4.94 & 36 & 5.57 & 42 & $-0.62^{* *}$ \\
\multirow{2}{*}{ Social TD claim } & first round & 5.00 & 18 & 6.05 & 21 & $-1.05^{* * *}$ \\
& full & 4.72 & 36 & 5.37 & 42 & $-0.65^{* *}$ \\
Social TD - Risk TD & first round & 4.81 & 18 & 6.00 & 21 & $-1.19^{* * *}$ \\
& full & -0.22 & 36 & -0.20 & 42 & -0.02 \\
& first round & -0.19 & 18 & -0.05 & 21 & -0.18 \\
\hline \hline
\end{tabular}

Note: The last column features t-tests on the difference in means between the gain and the loss treatment: $*(p<0.1),{ }^{* *}(p<0.05), * * *(p<0.01)$.

\subsubsection{Do elicited preferences and propensity to make mistakes correlate with behaviour in the traveler's dilemma?}

Further suggestive evidence for the mechanism can be gleaned from the correlations between individually elicited subject characteristics and strategic behaviour. In particular, we expect risk preferences and sophistication, but not social preferences, to correlate with net claims in the TD.

Table 5 lists the results of eight OLS regressions of net claims in the TD on various independent variables. Regressions 1 and 2 imply that the correlation between net claims in the TD and choices in the simple non-strategic TD is higher than the correlation between strategic play and the non-strategic TD that features a social motive. ${ }^{24}$ The absolute value of the coefficient in regression 1 may not be informative, because, by design, the non-strategic TD and the strategic TD are very similar and hence, drivers of behaviour unrelated to risk preferences, like focal points in the action space or the description of the game, could be at work in both. But the relative difference between the coefficients in regression 1 and regression 2 tells us that adding a social motive to the independent variable makes it less predictive of strategic play.

\footnotetext{
${ }^{24}$ Because Risk TD claim and Social TD claim both exhibit order effects (see table 9 in appendix B), regressions 1 and 2 are run over those subjects whose respective risk and social preferences were elicited before the strategic TD. Since the intersection of these two samples is zero, a valid regression featuring both Risk TD claim and Social TD claim cannot be run.
} 
Table 5 Determinants of net claims

\begin{tabular}{|c|c|c|c|c|c|c|c|c|}
\hline & 1 & 2 & 3 & 4 & 5 & 6 & 7 & 8 \\
\hline Risk TD claim & $\begin{array}{c}0.794^{* * *} \\
(0.10)\end{array}$ & & & & & & & \\
\hline Social TD claim & & $\begin{array}{c}0.588 * * * \\
(0.13)\end{array}$ & & & & & & \\
\hline HL switching point & & & $\begin{array}{c}-0.183^{*} \\
(0.10)\end{array}$ & & & $\begin{array}{l}-0.145 \\
(0.10)\end{array}$ & $\begin{array}{c}-0.073^{*} \\
(0.04)\end{array}$ & $\begin{array}{r}-0.008 \\
(0.03)\end{array}$ \\
\hline Dictator giving & & & & $\begin{array}{l}-0.067 \\
(0.10)\end{array}$ & & $\begin{array}{l}-0.109 \\
(0.09)\end{array}$ & $\begin{array}{l}0.008 \\
(0.04)\end{array}$ & $\begin{array}{l}0.012 \\
(0.03)\end{array}$ \\
\hline Quiz score & & & & & $\begin{array}{c}-0.165^{* *} \\
(0.07)\end{array}$ & $\begin{array}{c}-0.165^{* *} \\
(0.07)\end{array}$ & $\begin{array}{c}-0.095^{* * *} \\
(0.03)\end{array}$ & $\begin{array}{c}-0.094^{* * *} \\
(0.02)\end{array}$ \\
\hline Period(s) of TD play & 1 & 1 & 1 & 1 & 1 & 1 & $1-5$ & $6-10$ \\
\hline $\mathrm{N}$ & 39 & 39 & 71 & 71 & 71 & 71 & 355 & 355 \\
\hline R-squared & 0.473 & 0.321 & 0.048 & 0.007 & 0.070 & 0.119 & 0.042 & 0.052 \\
\hline
\end{tabular}

Regressions 3 through 5 indicate that a subject's HL switching point and her performance in the quiz, but not dictator giving, are correlated with claims in the first period of TD play. Since these independent variables do not exhibit significant order effects, we can run a regression over the entire sample of subjects and include measures of risk preferences, social preferences and sophistication. In regression 6 , the quiz score is the only significant independent variable. The HL switching points falls just short of the 10 percent level.

Regression 7 pools observations from the first 5 periods of TD play: risk preferences and sophistication exhibit the expected correlation with strategic behaviour. Regression 8 pools observations form the last 5 periods, after some learning would have taken place. In these periods, it is mainly subjects that did not fully understand the game (as captured by a low quiz score) that still deviate from Nash play, while the median subject now plays the lowest action. Thus, the impact of risk preferences becomes negligible.

In the questionnaire after the experiment we elicited the motives behind subjects' choices in the TD (see table 10 and 11 in appendix B). Subjects' answers are again more consistent with a risk preference explanation than a social preference explanation of the treatment effect. Subjects in the loss domain consider "trying to gain a lot" to be a more important reason to choose a high claim and "avoiding the risk of being undercut" to be a less important reason for choosing a low claim than subjects in the gain domain. 


\section{Further treatments}

\subsection{Loss avoidance and the gain-loss treatment}

In the gain-loss treatment positive as well as negative payoffs were possible. Subjects were paid a participation fee of 8 Euros, admissible claims lay between -5 and 0 , and $R$ was set at 3 Euros. The gain-loss treatment allows us to observe behaviour around the reference point, not just behaviour approaching it from the right or from the left as in the gain and the loss treatments, respectively. For comparability with the other treatments, we again think in terms of net claims $x$ and payoffs $z$. Hence, the experimentally induced reference point lies at $z=8$, which we obtain by adding the participation fee to the true reference point of zero.

A risk-preference-based explanation implies that average claims in the gain-loss treatment should lie between average claims in the loss and the gain treatment. And indeed, the observed distribution of net claims in Figure 3a peaks at around 5 , as opposed to 6 in the loss treatment and 3 in the gain treatment.

In order to devise a more stringent test of whether or not the observed behaviour is consistent with diminishing sensitivity, we use the experimental data to estimate a version of our cognitive hierarchy model in which the utility function takes the following form ${ }^{25}$

$$
U(z)=e^{-\delta\left[-\ln \left(\frac{z}{10.9}\right)\right]^{\gamma}} .
$$

Depending on the parameter values, this function (Prelec, 1998) can be convex, concave, S-shaped or have an inverted S-shape. Furthermore, when it has an Sshape, the parameter values endogenously pin down its point of inflection. ${ }^{26} \mathrm{We}$ are interested in whether the observed distribution of claims is best explained or rationalised by the exact shape of the value function that diminishing sensitivity implies. That is, whether our estimated value function is S-shaped with its point of infection at the experimentally induced reference point at $z=8$.

Our estimates are in table 12 in appendix B. As before, we estimate the cognitive hierarchy model both separately for each period and jointly under the restriction that $\gamma$ and $\delta$ remain constant. We also estimate the model under the risk neutrality restriction $(\gamma=1$ and $\delta=1)$. We reject the risk-neutrality restriction in favour of an S-shaped utility that bears a remarkable resemblance to what prospect theory

\footnotetext{
${ }^{25}$ We again perform all estimates using net claims. Dividing payoffs by the maximal gain (10.9) is a normalisation which ensures that the argument of the function lies in $[0,1]$.

${ }^{26}$ The function precludes a kink and we are therefore abstracting from loss aversion much like the many papers that assume a piecewise linear value function with a kink at the reference point abstract from diminishing sensitivity.
} 


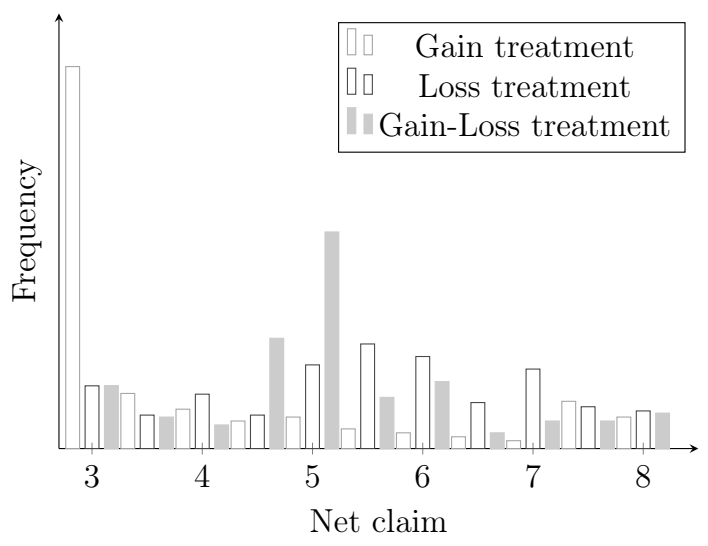

(a) Distribution of claims

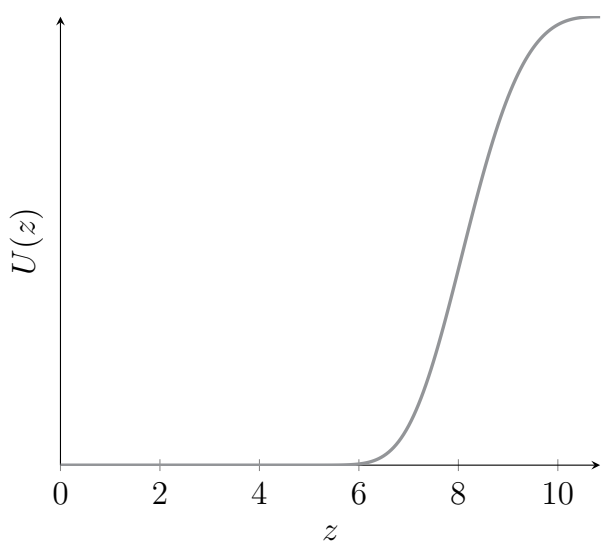

(b) Estimated utility function

Figure 3 Gain-loss treatment

would suggest. Figure $3 \mathrm{~b}$ plots the estimated utility function with estimates from the first period $(\hat{\gamma}=3$ and $\hat{\delta}=26)$.

To understand how a reference point of $z=8$ generates the pronounced peak in the frequency of observed claims at $x=5$, note that the S-shaped utility function implies that the value that a subject attaches to small increases in earnings is very high around the reference point. She will therefore be very keen to avoid earning less than $z=8$. That is, she may act almost as if to maximise her chance of not earning less than $z=8$. Since $R=3$, this is achieved by playing $x=5$.

Subjects in the gain-loss treatment play to avoid losses and this loss avoidance follows naturally from prospect theory's value function and strategic uncertainty. Our results thus also hint at a possible microfoundation for loss avoidance as an equilibrium selection principle, which Cachon and Camerer (1996) document in the context of a coordination game.

The gain-loss treatment also allows us to address a potential concern that our main treatment effect is a house money effect, by which subjects become more risk-loving if they are endowed with free money by the experimenter. The above results suggest that our framing works as intended, to the surprising extent that experimentally induced and theoretical reference points coincide. ${ }^{27}$

${ }^{27}$ More generally, evidence for house money effects is still limited. Thaler and Johnson (1990) mostly rely on an unincentivised part of their experiment to document the effect and Clark (2002) finds that house money effects do not seem to play a role in public good games, although Harrison (2007) shows that this statement is only true for the intensive margin of contributions. Note that if house money effects played a role in our experiment, our central implication that higher risk tolerance causes cooperation would remain in tact. 


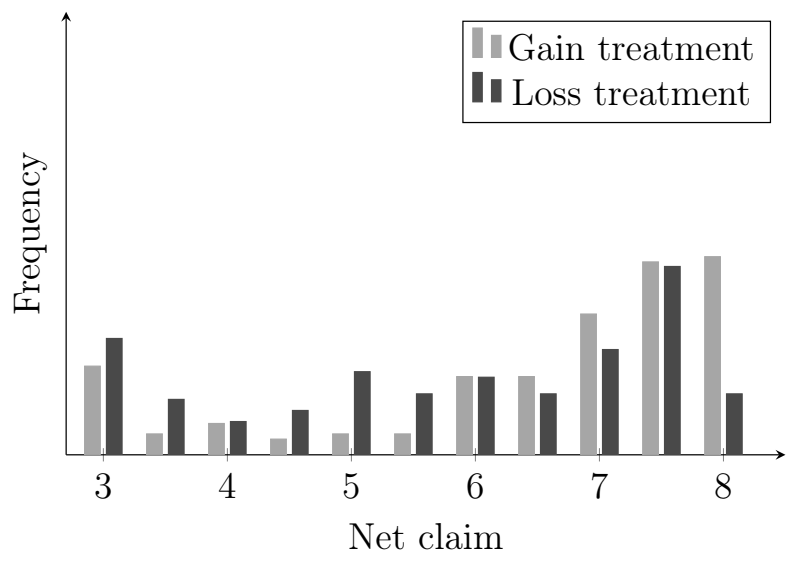

(a) Distribution of claims

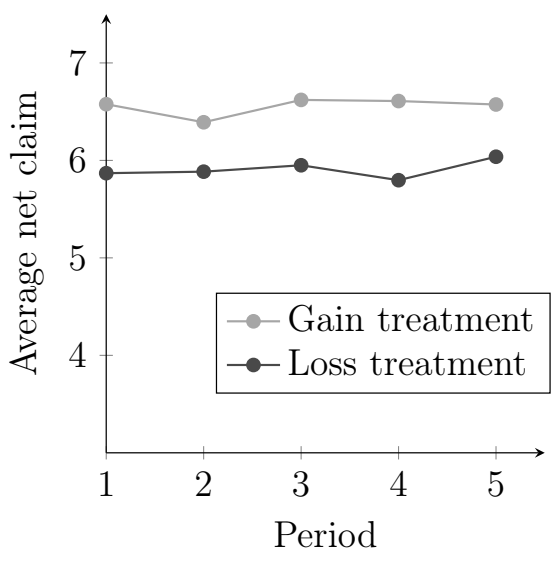

(b) Average claims per period

Figure 4 The traveler's dilemma with $R=0.5$

\subsection{The traveler's dilemma with a small $R$}

In experiment 1 , after five rounds of the TD with $R=3$, we let subjects play five additional rounds with $R=0.5$, both in the gain and the loss treatment. This change allows us to verify whether a lower reward/punishment parameter leads to higher average claims, as in previous studies (e.g. Capra et al. 1999). It also allows us to observe subjects' behaviour in a game in which we expect the impact of risk preferences on behaviour to be smaller. ${ }^{28}$

Figure $4 \mathrm{a}$ depicts the distribution of claims, pooling the 5 periods, while figure $4 \mathrm{~b}$ reports per-period averages. Average net claims are 6.55 and 5.91 in the gain and loss treatment respectively. In both treatments, we confirm previous findings that reducing $R$ increases average claims. Moreover, observed claims are higher in the gain treatment. ${ }^{29}$

This difference is consistent with subjects being less sophisticated in the loss domain and a low $R$ dampening the effect of asymmetries in risk preferences. Note that, in the presence of strategic uncertainty, a sophisticated player's optimal action is decreasing in $R$ (Baghestanian, 2014). However, in the loss domain a lower fraction of players make the adjustment, resulting in lower average net claims.

To further demonstrate that the results of the $R=0.5$ treatment are consistent

\footnotetext{
${ }^{28}$ In the limit case of $R=0$, risk preferences become completely irrelevant because playing the highest action becomes a dominant strategy.

${ }^{29}$ Because we let subjects play the $R=0.5$ part after our main treatment with $R=3$, results could be susceptible to order effects. At the same time, we have reason to believe order effects are small and working against the relationship we uncover. In particular, Capra et al. (1999) find that in within subject sequential treatments in which $R$ was varied, higher (lower) claims in an initial treatment lead to slightly higher (lower) claims in the following treatment.
} 
Table 6 Predicted and actual mean net claims when $R=0.5$

\begin{tabular}{cccc}
\hline \hline Treatment & Estimates from $R=3$ & Predicted mean & Actual mean \\
\hline Gain & $(\alpha, t, w)=(1.08,0.716,0.078)$ & 6.59 & 6.55 \\
Loss & $(\alpha, t, w)=(3.41,0.18,0.06)$ & 5.95 & 5.91 \\
\hline \hline
\end{tabular}

Note: Predicted mean net claims are obtained by using average parameter estimates over the 5 periods from table 2 .

with our suggested mechanism, we perform an out-of-sample forecasts of the model of section 4.2. That is, we generate predicted mean claims for $R=0.5$ using parameter estimates from the $R=3$ rounds. Table 6 demonstrates how the theoretically simulated mean is higher in the gain domain as well as how predicted and actual means are remarkably close.

The case of $R=0.5$ demonstrates that our main treatment effect arises primarily when raising one's claim entails a sizeable downside risk because potential punishment and forgone reward are high, i.e. it arises in high-risk situations like the real-world social dilemmas we seek to capture.

\section{Conclusion}

We find that individuals are more likely to take a chance on one another when losses are at stake. The prospect of losses can induce cooperation in a social dilemma because people's risk tolerance and lower sophistication in the loss domain drive them to deviate from Nash play. Our experiment also begins to pin down the scope of this mechanism. It is more likely to pay a role when there is much strategic uncertainty, as in the early periods of our experiment, and when the payoff variance is high, as in our treatments with $R=3$. An appreciation of how diminishing sensitivity impacts on strategic behaviour then also points to when and how a loss frame is likely to impact on behaviour in non-linear public good games, prisoner's dilemmas, coordination games and Bertrand competition.

Our results suggest that politicians who seek to foster cooperation amongst the different stakeholders to a reform or policy initiative may find it useful to evoke a loss frame. The loss frame may not only increase the perceived stakes through loss aversion, but also foster cooperation through the mechanism we uncover in this paper. Indeed, leaders that wish to garner support for war, will often exaggeratedly point to the "threat to our way of life" the enemy poses. Similarly, economic reforms are often advertised as the only way to "remain competitive" or "avoid slid- 
ing deeper into recession". However, our analysis also implies that cooperation will primarily emerge in uncertain settings and that it will decline as players gain experience. Therefore, a loss frame is probably most potently applied under exceptional circumstances and cannot be exploited repeatedly.

A manager may want to keep subordinates from cooperating to provide low effort or organising to demand higher wages. As a result, she may try to evoke the gain frame whenever possible, for example, by attempting to hide necessary cuts in real wages behind nominal wage increases. Abeler et al. (2011) and Fryer et al. (2012) find that by embedding payment schemes in the loss domain, loss aversion can be leveraged as a cheap way to increase effort in the lab and in the field respectively. Furthermore, De Quidt (2014) finds that doing so has no negative impact on employee participation. In light of this evidence, it is puzzling that the loss frame is not more widely used as incentive device. Our results speak to this puzzle. Where the organisational structure involves complicated games between employers and several employees, for example in a labor tournament setting, employee cooperation fuelled by risk tolerance may undermine the incentives to provide effort generated by loss aversion. 


\section{References}

Abeler, Johannes, Armin Falk, Lorenz Goette, and David Huffman. 2011. "Reference Points and Effort Provision." American Economic Review, 101(2): 470-92.

Arad, Ayala, and Ariel Rubinstein. 2012. "The 11-20 Money Request Game: A Level-k Reasoning Study." American Economic Review, 102(7): 3561-3573.

Baghestanian, Sascha. 2014. "Unraveling the Traveler' s Dilemma Puzzle-A Level-k Approach." Goethe University Frankfurt Working Paper.

Basu, Kaushik. 1994. "The Traveler's Dilemma: Paradoxes of Rationality in Game Theory." American Economic Review, 84(2): 391-395.

Becker, Tilman, Michael Carter, and Jörg Naeve. 2005. "Experts Playing the Traveler's Dilemma." University of Hohenheim, Germany Hohenheimer Diskussionsbeiträge $252 / 2005$.

Berejikian, Jeffrey. 1992. "Revolutionary Collective Action and the AgentStructure problem." American Political Science Review, 86(03): 647-657.

Bewley, Truman F. 2002. Why Wages Don't Fall During A Recession. Harvard University Press.

Booij, Adam S, Bernard M.S. Van Praag, and Gijs van de Kuilen. 2010. "A parametric analysis of prospect theory's functionals for the general population." Theory and Decision, 68(1-2): 115-148.

Brañas-Garza, Pablo, Maria Paz Espinosa, and Pedro Rey-Biel. 2011. "Travelers' types." Journal of Economic Behavior \& Organization, 78(1-2): 2536 .

Buchheit, Steve, and Nick Feltovich. 2011. "Experimental Evidence Of A SunkCost Paradox: A Study Of Pricing Behavior In Bertrand-Edgeworth Duopoly." International Economic Review, 52(2): 317-347.

Cachon, Gerard P., and Colin F. Camerer. 1996. "Loss-Avoidance and Forward Induction in Experimental Coordination Games." The Quarterly Journal of Economics, 111(1): 165-194. 
Camerer, C.F. 2003. "Prospect theory In The Wild: Evidence from the field." Colin F. Camerer, George Loewenstein, and Matthew. Rabin, eds., Advances in Behavioral Economics, 148-161.

Camerer, Colin F., Teck-Hua Ho, and Juin-Kuan Chong. 2004. "A Cognitive Hierarchy Model Of Games." The Quarterly Journal of Economics, 119(3): 861898.

Capra, C.M., J.K. Goeree, R. Gomez, and C.A. Holt. 1999. "Anomalous behavior in a traveler's dilemma?" The American Economic Review, 89(3): 678690 .

Capra, C. Monica, Jacob K. Goeree, Rosario Gomez, and Charles A. Holt. 2002. "Learning and Noisy Equilibrium Behavior in an Experimental Study of Imperfect Price Competition." International Economic Review, 43(3): 613-636.

Clark, Jeremy. 2002. "House money effects in public good experiments." Experimental Economics, 5(3): 223-231.

Coleman, James S. 1994. Foundations of Social Theory. Harvard University Press.

Cox, Caleb A. 2015. "Decomposing the effects of negative framing in linear public goods games." Economics Letters, 126: 63-65.

De Dreu, Carsten KW, and Christopher McCusker. 1997. "Gain-Loss Frames and Cooperation in Two-Person Social Dilemmas: A Transformational Analysis." Journal of Personality and Social Psychology, 72(5): 1093-1106.

De Heus, Peter, Niek Hoogervorst, and Eric Van Dijk. 2010. "Framing prisoners and chickens: Valence effects in the prisonerŠs dilemma and the chicken game." Journal of Experimental Social Psychology, 46(5): 736-742.

De Quidt, Jonathan. 2014. "Your loss is my gain: a recruitment experiment with framed incentives." SSRN Working Paper 2418218.

Fanis, Maria. 2004. "Collective Action Meets Prospect Theory: An Application to Coalition Building in Chile, 1973-75." Political Psychology, 25(3): 363-388.

Fehr, Ernst, and Klaus M Schmidt. 1999. "A Theory of Fairness, Competition, and Cooperation." Quarterly Journal of Economics, 114(3): 817-868. 
Fischbacher, Urs. 2007. "z-Tree: Zurich toolbox for ready-made economic experiments." Experimental Economics, 10(2): 171-178.

Fosgaard, Toke R, Lars Gårn Hansen, and Erik Wengström. 2014. "Understanding the nature of cooperation variability." Journal of Public Economics, 120: $134-143$.

Fryer, Roland G, Steven D Levitt, John List, and Sally Sadoff. 2012. "Enhancing the efficacy of teacher incentives through loss aversion: A field experiment." National Bureau of Economic Research Working Paper.

Goeree, Jacob K., Charles A. Holt, and Thomas R. Palfrey. 2002. "Quantal Response Equilibrium and Overbidding in Private-Value Auctions." Journal of Economic Theory, 104(1): 247 - 272.

Goeree, Jacob K, Charles A Holt, and Thomas R Palfrey. 2003. "Risk Averse Behavior in Generalized Matching Pennies Games." Games and Economic Behavior, 45(1): 97-113.

Goeree, J.K., and C.A. Holt. 2001. "Ten Little Treasures of Game Theory and Ten Intuitive Contradictions." American Economic Review, 91(5): 1402-1422.

Harrison, Glenn W. 2007. "House money effects in public good experiments: Comment." Experimental Economics, 10(4): 429-437.

Holt, Charles A., and Susan K. Laury. 2002. "Risk Aversion and Incentive Effects." American Economic Review, 92(5): 1644-1655.

Iturbe-Ormaetxe, Iñigo, Giovanni Ponti, Josefa Tomás, and Luis Ubeda. 2011. "Framing effects in public goods: Prospect Theory and experimental evidence." Games and Economic Behavior, 72(2): 439-447.

Kachelmeier, S.J. 1996. "Do Cosmetic Reporting Variations Affect Market Behavior? A Laboratory Study of the Accounting Emphasis on Unavoidable Costs." Review of Accounting Studies, 1(2): 115-140.

Kahneman, Daniel, and Amos Tversky. 1979. "Prospect Theory: An Analysis of Decision under Risk." Econometrica, 47(2): 263-292.

Kahn, Shulamit. 1997. "Evidence of Nominal Wage Stickiness from Microdata." American Economic Review, 87(5): 993-1008. 
Lim, Wooyoung, Alexander Matros, and Theodore L. Turoc. 2014. "Bounded Rationality and group size in Tullock contests: Experimental evidence." Journal of Economic Behavior \& Organization, 99: 155-167.

Mastanduno, Michael. 1992. "Framing the Japan Problem: The Bush Administration and the Structural Impediments Initiative." International Journal, 47(2): 235-264.

Mengel, Friederike. 2014. "Risk and Temptation: A Meta-Study on Social Dilemma Games." Available at SSRN 251999\%.

Mercer, Jonathan. 2005. "Prospect Theory and Political Science." Annual Review of Political Science, 8: 1-21.

Moore, Will H. 1995. "Rational Rebels: Overcoming the Free-Rider Problem." Political Research Quarterly, 48(2): 417-454.

Offerman, Theo, and Jan Potters. 2006. "Does Auctioning of Entry Licences Induce Collusion? An Experimental Study." Review of Economic Studies, 73(3): 769-791.

Oppenheimer, Joe, Stephen Wendel, and Norman Frohlich. 2011. "Paradox lost: Explaining and modeling seemingly random individual behavior in social dilemmas." Journal of Theoretical Politics, 23(2): 165-187.

Ostrom, Elinor. 1990. Governing the Commons: The Evolution of Institutions for Collective Action. Cambridge University Press.

Ostrom, Elinor. 2000. "Reformulating the Commons." Swiss Political Science Review, 6(1): 29-52.

Pauly, Louis W. 1992. "The Political Foundations of Multilateral Economic Surveillance." International Journal, 47(2): 293-327.

Prelec, Drazen. 1998. "The Probability Weighting Function." Econometrica, 66(3): 497-527.

Rojas, Christian. 2012. "The role of demand information and monitoring in tacit collusion." The RAND Journal of Economics, 43(1): 78-109.

Rotemberg, Julio J., and Garth Saloner. 1986. "A Supergame-Theoretic Model of Price Wars during Booms." The American Economic Review, 76(3): 390-407. 
Rubinstein, Ariel. 2007. "Instinctive and Cognitive Reasoning: A Study of Response Times." The Economic Journal, 117(523): 1243-1259.

Ruffle, Bradley J. 2013. "When do large buyers pay less? Experimental evidence." The Journal of Industrial Economics, 61(1): 108-137.

Stein, Janice Gross, and Louis W Pauly. 1992. "Choosing to Co-operate: How States Avoid Loss." International Journal, 47(2): 199-201.

Thaler, Richard H, and Eric J Johnson. 1990. "Gambling with the house money and trying to break even: The effects of prior outcomes on risky choice." Management science, 36(6): 643-660.

Tommasi, Mariano. 2004. "Crisis, Political Institutions, and Policy Reform The Good, the Bad, and the Ugly." Toward Pro-Poor Policies: Aid, Institutions and Globalization, Washington, DC: World Bank, 135-64.

Tymula, Agnieszka, Paul W. Glimcher, Ifat Levy, and Lior A. Rosenberg Belmaker. 2012. "Separating Risk and Ambiguity Preferences Across the Life Span: Novel Findings and Implications for Policy." Unpublished manuscript.

Velasco, Andres. 1998. "The Political Economy of Reform.", ed. Federico Sturzenegger and Mariano Tommasi, Chapter The Common Property Approach to the Political Economy of Fiscal Policy, 165-184. MIT.

Vis, Barbara. 2009. "The importance of socio-economic and political losses and gains in welfare state reform." Journal of European Social Policy, 19(5): 395-407.

Vis, Barbara, and Kees Van Kersbergen. 2007. "Why and how do Political Actors Pursue Risky Reforms?" Journal of Theoretical Politics, 19(2): 153-172.

Welch, David A. 1992. "The Politics and Psychology of Restraint: Israeli DecisionMaking in the Gulf War." International Journal, 47(2): 328-369.

Weyland, Kurt. 1996. "Risk Taking in Latin American Economic Restructuring: Lessons from Prospect Theory." International Studies Quarterly, 40(2): 185-207.

Weyland, Kurt Gerhard. 2002. The Politics of Market Reform in Fragile Democracies: Argentina, Brazil, Peru, and Venezuela. Princeton University Press. 


\section{Appendix}

\section{A Proofs}

Proof of Proposition 1. The difference between the lhs and rhs of equation (1) is increasing in $p$, positive when $p=1$ and negative when $p=0$. There thus exists a unique threshold for which player 1 is indifferent between playing 3 and $m$. This threshold is given by

$$
p^{*}=\frac{U(3)-U(3-R)}{U(3)-U(3-R)+U(m+R)-U(3+R)},
$$

which is decreasing in $m$.

To show that $p_{i}^{*}<p_{j}^{*}$ is to show that $\frac{1}{p_{i}^{*}}>\frac{1}{p_{j}^{*}}$ for $i, j \in\{a, n, l\}$ and $i \neq j$. We have that

$$
\frac{1}{p^{*}}=1+\frac{U(m+R)-U(3+R)}{U(3)-U(3-R)}
$$

By the mean value theorem, we can write

$$
\frac{1}{p^{*}}=1+\frac{((m+R)-(3+R)) U^{\prime}(c)}{(3-(3-R)) U^{\prime}(b)}
$$

with $m+R>c>3+R$ and $3>b>3-R$. From the definitions of risk preferences and the fact that $c>b$ it follows that $\frac{U^{\prime}(c)}{U^{\prime}(b)}>1$ for a risk loving individual, $\frac{U^{\prime}(c)}{U^{\prime}(b)}=1$ under risk neutrality, and $\frac{U^{\prime}(c)}{U^{\prime}(b)}<1$ if the individual is risk averse. Consequently, $p_{l}^{*}<p_{n}^{*}<p_{a}^{*}$.

Proof of Proposition 2. When $U\left(z_{1} ; z_{2}\right)=z_{1}+\beta z_{2}$, the best deviation from $x_{1}=3$ is either $x_{1}=m$ or $x_{1}=m+0.1$, depending on whether

$$
m+R+\beta(m-R) \geq m+0.1+\beta(m+0.1)
$$

that is, on whether $\beta \leq \frac{R-0.1}{R+0.1} \equiv \hat{\beta}$. If $\beta \leq \hat{\beta}$, the best deviation is $x_{1}=m$ and player 1 finds it strictly optimal to deviate if and only if

$$
p(m+R+\beta(m-R))+(1-p)(\beta 3+(3-R))>p(3+R+\beta(3-R))+(1-p)(3+3 \beta) .
$$


The difference between the lhs and rhs of equation (5) is increasing in $p$, positive at $p=1$, negative at $p=0$ and equal to zero at

$$
p_{\beta \leq \hat{\beta}}^{*}=\frac{R}{m+R-3+(m-3) \beta},
$$

which is decreasing in $\beta$ and $m$.

When $\beta>\hat{\beta}$, the best deviation is $x_{1}=m+0.1$ and player 1 finds it strictly optimal to deviate if and only if

$p(m+0.1+\alpha(m+0.1))+(1-p)(\beta 3+(3-R))>p(3+R+\beta(3-R))+(1-p)(3+3 \beta)$.

The difference between the lhs and rhs of this inequality is again increasing in $p$, positive at $p=1$, negative at $p=0$ and equal to zero at

$$
p_{\beta>\hat{\beta}}^{*}=\frac{10 R}{10(m+(m+R) \beta-29(1+\beta))},
$$

which is also decreasing in $\beta$ and $m$. To conclude the proof, let $p_{\beta}^{*}$ be equal to $p_{\beta \leq \hat{\beta}}^{*}$ for $\beta \leq \hat{\beta}$ and to $p_{\beta>\hat{\beta}}^{*}$ for $\beta>\hat{\beta}$ and note that $p_{\beta}^{*}$ is continuous in $\beta$ because $p_{\beta \leq \hat{\beta}}^{*}=p_{\beta>\hat{\beta}}^{*}$ when $\beta=\hat{\beta}$. 


\section{B Additional material}

Table 7 The HL risk preference elicitation task in the gain treatment

\begin{tabular}{cccc}
\hline \hline Row & Option L & Option R & Implied $\alpha$ \\
\hline 1 & 6 with $p=\frac{1}{10} ; 5$ with $p=\frac{9}{10}$ & 10.5 with $p=\frac{1}{10} ; 0.5$ with $p=\frac{9}{10}$ & $\alpha \geq 3.32$ \\
2 & 6 with $p=\frac{2}{10} ; 5$ with $p=\frac{8}{10}$ & 10.5 with $p=\frac{2}{10} ; 0.5$ with $p=\frac{8}{10}$ & $2.29 \leq \alpha<3.32$ \\
3 & 6 with $p=\frac{3}{10} ; 5$ with $p=\frac{7}{10}$ & 10.5 with $p=\frac{3}{10} ; 0.5$ with $p=\frac{7}{10}$ & $1.75 \leq \alpha<2.29$ \\
4 & 6 with $p=\frac{4}{10} ; 5$ with $p=\frac{6}{10}$ & 10.5 with $p=\frac{4}{10} ; 0.5$ with $p=\frac{6}{10}$ & $1.34 \leq \alpha<1.75$ \\
5 & 6 with $p=\frac{5}{10} ; 5$ with $p=\frac{5}{10}$ & 10.5 with $p=\frac{5}{10} ; 0.5$ with $p=\frac{5}{10}$ & $1 \leq \alpha<1.34$ \\
6 & 6 with $p=\frac{6}{10} ; 5$ with $p=\frac{4}{10}$ & 10.5 with $p=\frac{6}{10} ; 0.5$ with $p=\frac{4}{10}$ & $0.68 \leq \alpha<1$ \\
7 & 6 with $p=\frac{7}{10} ; 5$ with $p=\frac{3}{10}$ & 10.5 with $p=\frac{7}{10} ; 0.5$ with $p=\frac{3}{10}$ & $0.37 \leq \alpha<0.68$ \\
8 & 6 with $p=\frac{8}{10} ; 5$ with $p=\frac{2}{10}$ & 10.5 with $p=\frac{8}{10} ; 0.5$ with $p=\frac{2}{10}$ & $0.018 \leq \alpha<0.37$ \\
9 & 6 with $p=\frac{9}{10} ; 5$ with $p=\frac{1}{10}$ & 10.5 with $p=\frac{9}{10} ; 0.5$ with $p=\frac{1}{10}$ & $0<\alpha<0.018$ \\
10 & 6 with $p=\frac{10}{10} ; 5$ with $p=\frac{0}{10}$ & 10.5 with $p=\frac{10}{10} ; 0.5$ with $p=\frac{0}{10}$ & $\alpha \cong 0$ \\
\hline \hline
\end{tabular}

Note: Values in the last column obtain by assuming a utility of the form $U(x)=x^{\alpha}$. The task in the loss treatment is identical, except that 11 is subtracted from each outcome.

Table 8 The dictator task in the gain treatment

\begin{tabular}{ccc}
\hline \hline Choice & \multicolumn{1}{c}{ Consequences } \\
\hline 1 & you obtain $11 ;$ the other person obtains 3 \\
2 & you obtain $10 ;$ the other person obtains 4 \\
3 & you obtain & $9 ;$ the other person obtains 5 \\
4 & you obtain & $8 ;$ the other person obtains 6 \\
5 & you obtain & $7 ;$ the other person obtains 7 \\
6 & you obtain & $6 ;$ the other person obtains 8 \\
7 & you obtain & $5 ;$ the other person obtains 9 \\
8 & you obtain & $4 ;$ the other person obtains 10 \\
9 & you obtain & $3 ;$ the other person obtains 11 \\
\hline \hline
\end{tabular}

Note: The task in the loss treatment is identical except that 11 is subtracted from each outcome. 
Table 9 Order effects in elicited preferences

\begin{tabular}{lcccccc}
\hline \hline \multirow{2}{*}{ HL switching point } & \multicolumn{5}{c}{ First round } & \multicolumn{4}{c}{ Last round } \\
& Treatment & Mean & $\mathrm{N}$ & Mean & $\mathrm{N}$ & Difference \\
\hline \multirow{3}{*}{ HL switching point $(<11)$} & Gain & 6.72 & 18 & 6.94 & 18 & -0.22 \\
& Loss & 5.62 & 21 & 6.28 & 21 & -0.66 \\
& Gain & 6.19 & 16 & 6.44 & 16 & -0.25 \\
Dictator giving & Loss & 5.35 & 20 & 5.79 & 19 & -0.44 \\
& Gain & 3.17 & 18 & 3.11 & 18 & 0.05 \\
Risk TD claim & Loss & 3.62 & 21 & 2.81 & 21 & 0.81 \\
& Gain & 5.00 & 18 & 4.89 & 18 & 0.11 \\
Social TD claim & Loss & 6.05 & 21 & 5.10 & 21 & $0.95^{* *}$ \\
& Gain & 4.81 & 18 & 4.64 & 18 & 0.16 \\
& Loss & 6.00 & 21 & 4.74 & 21 & $1.26^{* * *}$ \\
\hline \hline
\end{tabular}

Note: The last column features t-tests on the difference in means between subjects who performed the task in the first and the last round: * $(p<0.1),{ }^{* *}(p<0.05)$, *** $(p<0.01)$.

Table 10 Self-reported explanations of play (importance on a 1 to 4 scale)

\begin{tabular}{|c|c|c|c|c|c|}
\hline & \multicolumn{2}{|c|}{ Gains } & \multicolumn{2}{|c|}{ Losses } & \multirow[b]{2}{*}{ Difference } \\
\hline & Mean & $\mathrm{N}$ & Mean & $\mathrm{N}$ & \\
\hline \multicolumn{6}{|l|}{ Reasons to choose a high claim } \\
\hline - try to gain a lot & 2.38 & 36 & 2.71 & 42 & $-.32^{*}$ \\
\hline - let the other gain a lot & 2.3 & 36 & 2.16 & 42 & .13 \\
\hline - reward who chooses a high claim & 2.44 & 36 & 2.4 & 42 & .03 \\
\hline - it is fair & 2.3 & 36 & 2.4 & 42 & -.09 \\
\hline \multicolumn{6}{|l|}{ Reasons to choose a low claim } \\
\hline - avoid the risk of being undercut & 3.69 & 36 & 3.26 & 42 & $.43^{* * *}$ \\
\hline - let the other gain little & 2 & 36 & 2.3 & 42 & -.309 \\
\hline - punish who plays a low claim & 2 & 36 & 2.42 & 42 & $-.42^{* * *}$ \\
\hline - it is rational & 3.08 & 36 & 3.04 & 42 & -.03 \\
\hline
\end{tabular}

Note: The last column features t-tests on the difference in means between the gain and the loss treatment: * $(p<0.1),{ }^{* *}(p<0.05),{ }^{* * *}(p<0.01)$. 
Table 11 Self-reported opinions on social norms (\% of "yes")

\begin{tabular}{|c|c|c|c|c|c|}
\hline & \multicolumn{2}{|c|}{ Gains } & \multicolumn{2}{|c|}{ Losses } & \multirow[b]{2}{*}{ Difference } \\
\hline & Mean & $\mathrm{N}$ & Mean & $\mathrm{N}$ & \\
\hline \multicolumn{6}{|l|}{ A plays a high claim and $\mathrm{B}$ a low one } \\
\hline - is B unfair? & $25 \%$ & 36 & $23.8 \%$ & 42 & $1.2 \%$ \\
\hline - would you incur a cost to punish B ? & $41.6 \%$ & 36 & $38.1 \%$ & 42 & $3.5 \%$ \\
\hline
\end{tabular}

Note: The last column features t-tests on the difference in means between the gain and the loss treatment: * $(p<0.1),{ }^{* *}(p<0.05),{ }^{* * *}(p<0.01)$.

Table 12 Estimates for the gain-loss treatment

\begin{tabular}{|c|c|c|c|c|c|c|c|}
\hline Treatment & Period & Restriction & $\gamma$ & $\delta$ & $t$ & $w$ & $\log L$ \\
\hline \multirow[t]{8}{*}{ Gain-Loss } & 1 & none & $3^{* * *}$ & $28^{* * *}$ & 0.21 & 0.15 & -120.634 \\
\hline & & & $(0.261)$ & $(6.045)$ & $(0.096)$ & $(0.053)$ & \\
\hline & 2 & none & $\begin{array}{c}3.5^{* * *} \\
(0.222)\end{array}$ & $\begin{array}{c}34^{* * *} \\
(5.319)\end{array}$ & $\begin{array}{c}0.21 \\
(0.0849)\end{array}$ & $\begin{array}{c}0 \\
(0.023)\end{array}$ & -128.64 \\
\hline & 3 & none & $\begin{array}{c}4^{* * *} \\
(0.196)\end{array}$ & $\begin{array}{l}22^{\text {*** }} \\
(2.87)\end{array}$ & $\begin{array}{c}0.41 \\
(0.131)\end{array}$ & $\begin{array}{c}0.05 \\
(0.047)\end{array}$ & -117.331 \\
\hline & 4 & none & $\begin{array}{c}4^{* * *} \\
(0.223)\end{array}$ & $\begin{array}{c}19^{* * *} \\
(3.198)\end{array}$ & $\begin{array}{c}0.31 \\
(0.122)\end{array}$ & $\begin{array}{c}0.05 \\
(0.05)\end{array}$ & -122.311 \\
\hline & 5 & none & 4 & 22 & 0.21 & 0.05 & -129.312 \\
\hline & & & $(0.832)$ & $(7.226)$ & $(0.064)$ & $(0.024)$ & \\
\hline & all 5 & $\gamma \& \delta$ const & $4^{* * *}$ & $19^{* * *}$ & & & -623.583 \\
\hline
\end{tabular}

Note: Bootstrapped standard errors in parentheses; significance levels from a likelihoodratio test against the restriction $\gamma=\delta=1:{ }^{*}(p<0.1),{ }^{* *}(p<0.05),{ }^{* *}(p<0.01)$. 


\section{Online Appendix}

\section{Instructions for the loss treatment of experiment 2 (translation from French)}

Welcome to the experimental laboratory of the Toulouse School of Economics and thank you for participating in this experiment. The data we collect is anonymous and will be used for scientific purposes only.

You received $\mathbf{1 1} €$ as a payment for your participation.

The total amount of money you will earn depends on your decisions as well as on those of the other participants.

Please do not ask questions out loud during the experiment. If you do have a question or if an error message that you do not understand appears on your screen, please raise your hand and we will answer your question individually. Also, we kindly ask you not to talk or in any other way communicate with other participants during this experiment.

Some general information:

- If during the experiment you obtain a negative amount of money, you will have to reimburse the corresponding sum by using part of the $11 €$ that you received at the beginning of the experiment. Earning a negative amount thus implies a loss.

- During the experiment, every time you are paired with another person he or she will be a different person (you will never be paired with the same person twice).

- Only some of your decisions will be relevant for your final payment, as explained in detail later on. But it is important to keep in mind that each decision might determine your final earnings. Thus, it is essential that you understand how your earnings in each decision problem are calculated.

- The expression "selected at random" means that all possible outcomes have the same probability. For example, if one of three given numbers is "selected at random", each number has a probability of $1 / 3$ of being selected. 
- You have to use the period as decimal separator and even if you want to insert an integer you have to type the number followed by the decimal part (e.g. "1" has to be written as "1.0"). In order to insert a negative number just add a "-" (e.g. "-1.0").

The experiment consists of two parts, A and B. Part A is about to begin.

Please do NOT turn the page before we instruct you to do so. Thank you. 


\section{PART A}

Part A consists of 12 periods. Only one of the 12 periods will be selected at random at the end of the experiment and will determine your earnings.

Periods 2 to 11 are identical and below you are given the instructions for these periods. Periods 1 and 12 are slightly different and the instructions will appear directly on your screen.

\section{Instructions for periods 2 to 11}

During each period from 2 to 11, you will be paired with another participant (a different participant in each period). Each of you has to choose a value between $\mathbf{- 8 . 0} €$ and $-3.0 €(-8 €$ and $-3 €$ included $)$. Half units are allowed: e.g. "-5.5" means negative 5 Euros and 50 Euro-cents. The values you are allowed to choose in ascending order are:

$$
\begin{array}{lllllllllll}
-8.0 & -7.5 & -7.0 & -6.5 & -6.0 & -5.5 & -5.0 & -4.5 & -4.0 & -3.5 & -3.0
\end{array}
$$

Note that, as you are dealing with negative numbers, the smallest number is the one that has the highest absolute value (e.g. -4 is smaller than -3.5 ).

Your earnings are determined as follows (remember that earning a negative amount represents a loss):

- If the values you and your partner choose are equal, each of you earns that value.

- If the two values differ, each of you earns the minimum of the two values. In addition, $3 €$ will be added to the earnings of the person who chose the smaller value and $3 €$ will be deducted from the earnings of the person who chose the larger value.

For example, if you and your partner both choose -4.0 : both of you earn $-4 €$ (you both lose $4 €)$.

If you choose -5.0 and your partner chooses -4.5 : you earn $-5 €+3 €=-2 €$ (you lose $2 €$ ) and your partner earns $-5 €-3 €=-8 €$ (your partner loses $8 €$ ).

If you choose -3.0 and your partner chooses -3.5 : you earn $-3.5 €-3 €=-6.5 €$ (you lose $6.5 €$ ) and your partner earns $-3.5 €+3 €=-0.5 €$ (your partner loses $0.5 €$ ). Make sure you understand how the earnings in these examples are calculated. 


\section{Note: All the remaining instructions appeared on screen.}

\section{Instructions for period 1 (or 12)}

In this period you are paired with another participant (with whom you neither have been already nor will again be paired). Both of you face the same two scenarios and in each scenario you have to make a decision that impacts on your earnings as well as those of your partner. Randomly, either one of your two decisions or one of the two decisions made by your partner is selected to determine your actual earnings for this period. So, unlike in periods 2-11, earnings are not simultaneously determined by your decision and the one of your partner.

For example, if your decision from the 2nd scenario is selected, it will determine your earnings as well as your partner's earnings for this period. If your partner's decision from the 1st scenario is selected, his/her decision determines his/her earnings as well as yours for this period.

Scenario 1: Just like in periods 2-11, you have to choose a value between $-8 €$ and $-3 €(-8.0$ and -3.0 are included; half-units are allowed) and the same rules apply to calculate your earnings and those of your partner. The only difference is that the value of your partner is not chosen by himself/herself, but instead, randomly by the computer.

If, for example, you choose -5.0 and the computer -4.5 , you earn $-5 €+3 €=-2 €$ (you lose $2 €$ ) and your partner earns $-5 €-3 €=-8 €$ (loses $8 €)$.

Scenario 2: You have to choose one of the options described in the table. The chosen option determines your earnings as well as those of your partner (we remind you that earning a negative value corresponds to a loss). As you move down the table, the loss of your partner decreases, while your loss increases.

If, for example, you choose option 3 , you receive $-2 €$ (you lose $2 €$ ) and your partner receives $-6 €($ loses $6 €)$. 


\begin{tabular}{cl}
\hline \hline Choice & \multicolumn{1}{c}{ Consequences } \\
\hline 1 & you obtain 0 ; the other person obtains -8 \\
2 & you obtain -1; the other person obtains -7 \\
3 & you obtain -2; the other person obtains -6 \\
4 & you obtain -3; the other person obtains -5 \\
5 & you obtain -4; the other person obtains -4 \\
6 & you obtain -5; the other person obtains -3 \\
7 & you obtain -6; the other person obtains -2 \\
8 & you obtain -7; the other person obtains -1 \\
9 & you obtain -8; the other person obtains 0 \\
\hline \hline
\end{tabular}

\section{Instructions for period 12 (or 1 )}

In this period, you are not paired with another participant. You will face two scenarios and one of your choices will randomly be selected to determine your earnings for this period.

Scenario 1: Just like in periods 2-11, you have to choose a value between $-8 €$ and $-3 €(-8.0$ and -3.0 are included; half-units are allowed) and the same rules apply to calculate your earnings. The difference is that the other value used to calculate your earnings is not chosen by another person but randomly by the computer.

If, for example, you choose -5.0 and the computer -4.5 , you earn $-5 €+3 €=-2 €$ (you lose $2 €)$.

Scenario 2: You face 10 decision problems (described in the table). A single decision problem will randomly be selected to determine your earnings. You have to choose between option $\mathbf{L}$ and option $\mathbf{R}$. Take a look at decision 1 in the table. With option L, you earn $-5 €$ (lose $5 €$ ) with a probability of $1 / 10$ and you earn $-6 €($ lose $6 €)$ with a probability of $9 / 10$. With option $R$, you earn $-0.5 €$ (lose $0.5 €$ ) with a probability of $1 / 10$ and you earn $-10.5 €$ (lose $10.5 €$ ) with a probability of $9 / 10$. The other decision problems are similar, except for the fact that as you move down the table, the probability of the most favourable outcome for each option increases. Moreover, we note that for decision problem 10 in the last line, both options definitely bring you the most favourable outcome and you actually have to choose between receiving $-5 €($ loosing $5 €)$ or $-0.5 €(\operatorname{losing} 0.5 €)$ ). Suppose in decision 7 you chose option $\mathrm{R}$ and decision 7 is selected to determine your earnings. With a probability of $7 / 10$ you receive $-0.5 €$ (lose $0.5 €$ ) and with a probability 
of $3 / 10$ you receive $-10.5 €$ (lose $10.5 €)$.

\begin{tabular}{cll}
\hline \hline Row & Option L & Option R \\
\hline 1 & -5 with $p=\frac{1}{10} ;-6$ with $p=\frac{9}{10}$ & -0.5 with $p=\frac{1}{10} ;-10.5$ with $p=\frac{9}{10}$ \\
2 & -5 with $p=\frac{2}{10} ;-6$ with $p=\frac{8}{10}$ & -0.5 with $p=\frac{2}{10} ;-10.5$ with $p=\frac{8}{10}$ \\
3 & -5 with $p=\frac{3}{10} ;-6$ with $p=\frac{7}{10}$ & -0.5 with $p=\frac{3}{10} ;-10.5$ with $p=\frac{7}{10}$ \\
4 & -5 with $p=\frac{4}{10} ;-6$ with $p=\frac{6}{10}$ & -0.5 with $p=\frac{4}{10} ;-10.5$ with $p=\frac{6}{10}$ \\
5 & -5 with $p=\frac{5}{10} ;-6$ with $p=\frac{5}{10}$ & -0.5 with $p=\frac{5}{10} ;-10.5$ with $p=\frac{5}{10}$ \\
$6 \quad-5$ with $p=\frac{6}{10} ;-6$ with $p=\frac{4}{10}$ & -0.5 with $p=\frac{6}{10} ;-10.5$ with $p=\frac{4}{10}$ \\
7 & -5 with $p=\frac{7}{10} ;-6$ with $p=\frac{3}{10}$ & -0.5 with $p=\frac{7}{10} ;-10.5$ with $p=\frac{3}{10}$ \\
$8 \quad-5$ with $p=\frac{8}{10} ;-6$ with $p=\frac{2}{10}$ & -0.5 with $p=\frac{8}{10} ;-10.5$ with $p=\frac{2}{10}$ \\
$9 \quad-5$ with $p=\frac{9}{10} ;-6$ with $p=\frac{1}{10}$ & -0.5 with $p=\frac{9}{10} ;-10.5$ with $p=\frac{1}{10}$ \\
$10 \quad-5$ with $p=\frac{10}{10} ;-6$ with $p=\frac{0}{10}$ & -0.5 with $p=\frac{10}{10} ;-10.5$ with $p=\frac{0}{10}$ \\
\hline \hline
\end{tabular}




\section{PART B}

Part B is a quiz about periods 2-11 from Part A. There are 10 questions and you have 30 seconds per question (if you do not respond within the time limit, your response will be considered as incorrect). For your participation in the quiz you receive $\mathbf{9} €$ that will be added to you final payment of Part A. For every wrong answer, you will lose $0.5 €$ of your $9 €$ payment for the quiz. If the question asks you to give an estimate, the penalty for an incorrect estimate is $1 €$ and your estimate is considered correct if it lies between plus and minus 1 from the exact answer.

Suppose that in this period you chose the value -6.5 and you partner chose -6.0 .

- How much do you receive in this period?

- How much does your partner receive in this period?

How many admissible values are strict lower than -4.5 ?

Suppose that in this period you chose the value -7.0 and you receive $-4 €$. Which is the smallest value (the most negative one) that your partner could have chosen in this period?

Suppose that in this period your partner will choose -8.0 with a probability of $30 \%$ and -4.0 with a probability of $70 \%$.

- What are your average earnings if you choose -8.0?

- Which value would maximise your average gains (and thus minimise your average loss)?

Suppose that in this period your partner will choose -8.0 with a probability of $30 \%$ and -7.5 with a probability of $70 \%$.

- What are you average earnings if you choose -8.0 ?

- Which value would maximise your average gains (and thus minimise your average loss)?

What is your estimate for the average number of correct responses given by the other participants to the 8 first questions of this test?

What is your estimate for the number of questions that you answered correctly (for the first 8 questions of this test)? 


\section{Questionnaire}

The experiment is over. We now ask you to complete this questionnaire.

The questions concern periods 2-11 from Part A.

Which, according to you, is the fair value to choose?

Which is the least risky value?

For each of the following statements, indicate whether you think that it represents a valid reason (not at all important, of small importance, quite important, very important) to choose a high value (meaning a less negative value):

1. The other person will probably choose a high value and thus it is in my best interest to do the same.

2. The other person will probably choose a high value and I do not like to choose a value lower than hers.

3. It is the right thing to do because if everybody does so, both participants (partner and myself) benefit.

4. Choosing a high value is more risky than choosing a lower value, but I prefer trying my luck.

For each of the following statements, indicate whether you think that it represents a valid reason (not at all important, of small importance, quite important, very important) to choose a low value (meaning a more negative value):

1. I want to choose a lower value than the other person.

2. The other person will probably choose a low value and I do not want her value to be smaller than mine.

3. There is nothing bad about choosing a low value and it is in my interest to do so.

4. Choosing a low value is less risky than choosing a high value.

Suppose player A plays a high value and player B a low value.

- Do you think that player B is being unfair?

- Would you be willing to incur a personal cost to punish him? 